Published in Thin-Walled Structures, 134: 491-507, 2019.

\title{
Ultimate limit state based design versus allowable working stress based design for box girder crane structures
}

Dong Hun Lee ${ }^{\mathrm{a}}$, Sang Jin Kim ${ }^{\mathrm{b}}$, Man Seung Lee ${ }^{\mathrm{c}}$, and Jeom Kee Paik ${ }^{\mathrm{a}, \mathrm{b}, \mathrm{d}^{*}}$

a Department of Naval Architecture and Ocean Engineering, Pusan National University, Busan 46241, Republic of Korea

${ }^{b}$ The International Centre for Advanced Safety Studies (The Lloyd's Register Foundation Research Centre of Excellence), Pusan National University, Busan 46241, Republic of Korea

${ }^{c}$ POSCO Engineering and Construction, Incheon, 22009, Republic of Korea

${ }^{d}$ Department of Mechanical Engineering, University College London, London WC1E 7JE, $U K$

*Corresponding author at: Tel.: $+82 \quad 51 \quad 510$ 2429; E-mail address: jeompaik@gmail.com

\begin{abstract}
It is now well recognized that limit states are a much better basis than allowable working stresses for economical, yet safe design of structures. The objective of the present paper is to apply the ultimate limit states as the structural design criteria of a box girder crane. For this purpose, a reference box girder crane structure which was originally designed and constructed based on the allowable working stress criteria and still in operation is selected. The structure is then redesigned applying the ultimate limit state criteria, where other types of limit states such as serviceability limit states and fatigue limit states are also considered. Nonlinear finite
\end{abstract}


element method is applied to analyze the progressive collapse behaviour of the structure until and after the ultimate limit state is reached. While the ultimate strength or maximum load-carrying capacity of the structure has never been realized as far as the allowable working stress based design method is applied, this study starts with identifying it by the nonlinear finite element method. The structural weight was then attempted to minimize by changing structural member dimensions while the ultimate strength remains the same. It is concluded that the ultimate limit state based design method provides more economical, yet safe structures, compared with the allowable working stress based design method. Considerations for the serviceability limit states are addressed in the paper, while those for the fatigue limit states are presented in a separate article.

Keyword: Box girder crane structures; Ultimate limit states; Serviceability limit states; Nonlinear finite element method; Allowable working stress.

\section{Introduction}

Examples of steel plated structure include ships, offshore installations, bunkers, box girder bridges and box girder cranes $[1,2]$. In the past, steel plated structures have typically been designed using the allowable working stress based design method (AWSDM). In the AWSDM, the structural design criterion is that the working stress under the applied design loads must be smaller than an allowable stress. On the other hand, the ultimate limit state based design method (ULSDM) is based on the criterion of the ultimate limit state or ultimate strength or maximum load-carrying capacity which is represented by point B in Fig.1, where the ultimate strength should not be smaller than the applied design loads with an adequate margin of safety [2]. In the AWSDM, point B remains unknown although a simplified buckling strength check represented by point A may be applied. This means that the AWSDM is unable to define the true margin of structural safety that can be determined only by a comparison between the ultimate strength and the applied design loads. 


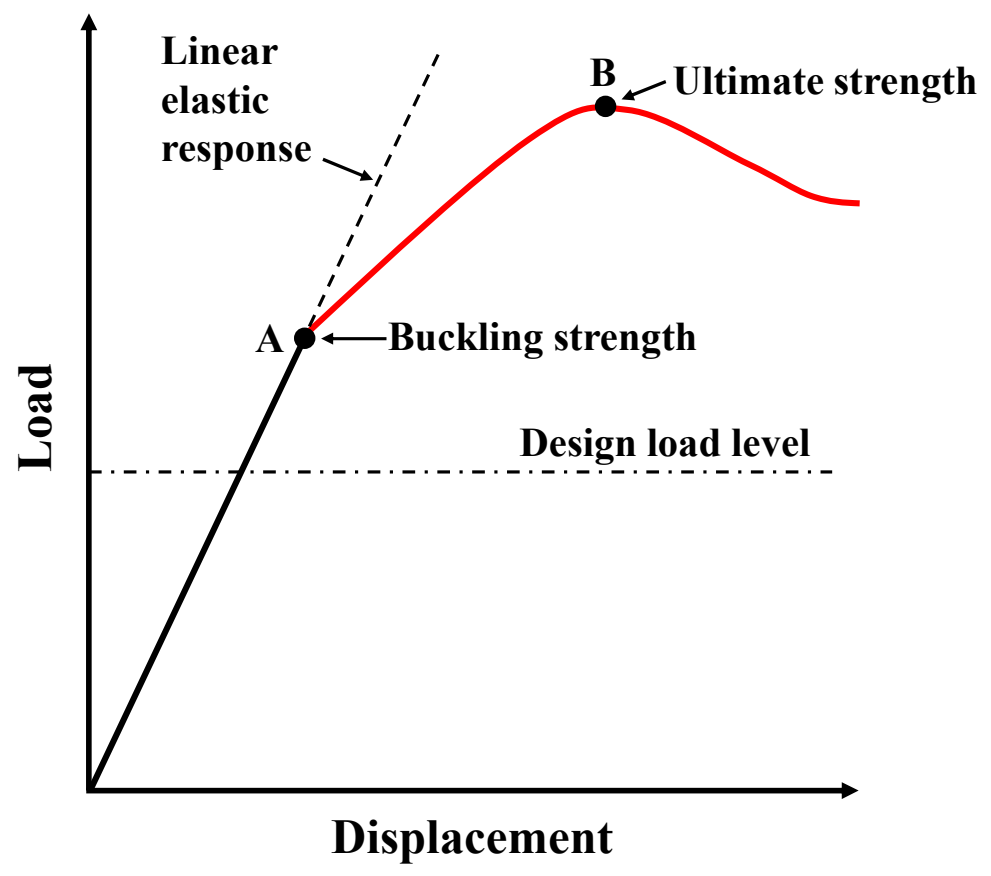

Fig. 1. Ultimate limit state of structures [2].

For ships and offshore structures, a number of contributions toward the application of the ULSDM has been undertaken [3-8]. Also, in the civil engineering field for land-based structures, the ULSDM has been applied [9-13]. The determination of the ultimate strength for structural components such as plates and stiffened panels under various conditions has been undertaken by the experimental test and the nonlinear finite element method [14-26]. Similar contributions have also been performed in box-shaped structures [27-43]. Kotełko et al. [44] carried out a sensitivity analysis of thin-walled box girders subjected to pure bending. They concluded that a redundancy of the load-carrying capacity of box-section girder is sensitive to the yield stress deviation, implying that the AWSDM based on the yield stress of material has the uncertainty to structural safety.

The main objective of the present study is to apply the ULSDM for box girder crane structures which have originally been designed using the AWSDM. Additionally, the serviceability limit state is considered to secure the operability and functionality of the 
crane structures. The reference structure is part of a real crane system and it has been successfully operated without structural safety issues. The structure is made of SM490 steel but the manufacturer of the crane wants to use a high tensile steel of HSB500 which is a very modern material. This is a motive of the study. The manufacturer wants to keep the same amount of maximum load-carrying capacity as the reference structure which was originally designed using the ASWDM, while the structural weight or building cost must be minimized or at least be similar to the original structure because of using a high tensile steel.

For this purpose, the progressive collapse behaviour of the structure until and after it reaches the ultimate strength was first determined by using the nonlinear finite element method. Case studies were then undertaken with varying the structural member dimensions as well as material while keeping the same (similar) maximum load-carrying capacity and minimizing the structural weight. It is obvious that the ULSDM is useful to achieve the goals and it is concluded that the ULSDM is much better than the ASWDM in terms of designing more economical, yet safe structures. 


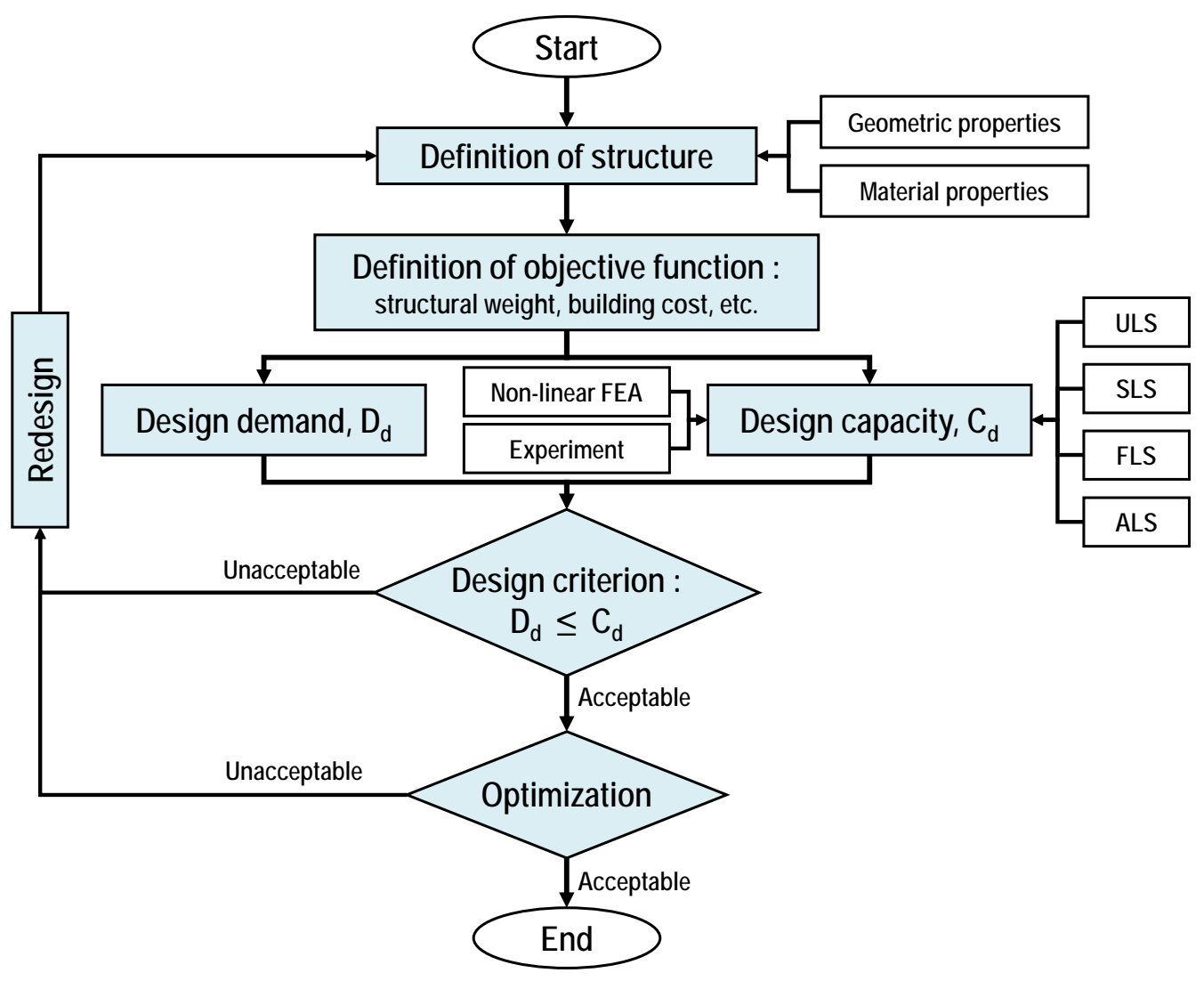

Fig. 2. Flowchart of the limit state based structural design optimization applied in the present study.

\section{The Procedure for the Limit State based Structural Design Optimization}

In the traditional ASWDM, the focus is on keeping the working stresses resulting from the design loads under a certain working stress level that is usually based on successful past experience:

$$
\sigma<\sigma_{a}
$$

where $\sigma$ is the working stress and $\sigma_{a}$ is the allowable stress which is usually specified by regulatory bodies or classification societies as some fraction of the mechanical properties of materials, e.g., uniaxial yield or ultimate tensile strength.

On the other hand, the limit state approach is based on limit states as described in Fig. 2 [2]. It starts with the definition of target structures to be designed where the conditions of functionality and operability as well as geometric and material properties 
are identified. In the next step, the objective function of the structural design is defined. Typically, the structural optimization is aiming at minimizing structural weight or building costs while keeping the structural safety.

In the next step, the design demand or applied design loads are defined as follows:

$$
D_{d}=\gamma_{d} D_{k}
$$

where $D_{d}$ is the design demand, $D_{k}$ is the characteristic value of the demand which is the mean value of applied loads, and $\gamma_{d}$ is the partial safety factor associated with the uncertainties of applied loads.

Also, the design capacity or the maximum load-carrying capacity is defined as follows:

$$
C_{d}=\gamma_{c} C_{k}
$$

where $C_{d}$ is the design capacity, $C_{k}$ is the characteristic value of the design capacity which is the mean value of the limit states, and $\gamma_{c}$ is the partial safety factor associated with the uncertainties of the limit states.

In Equation (3), four types of limit states are relevant, namely the ultimate limit states (ULS), the serviceability limit states (SLS), the fatigue limit states (FLS) and the accidental limit states (ALS). In the present study, both the ULS and the SLS are considered. The characteristic value of the ULS or the ultimate strength or the maximum load-carrying capacity can be determined by experiments or nonlinear finite element methods. This study applies the nonlinear finite element method to determine the ultimate strength of the box girder crane structures.

Once both the design demand and the design capacity are determined, the structural constraints are applied to be safe as follows:

$$
\alpha=\frac{C_{d}}{D_{d}} \geq 1
$$

where $\alpha$ is the safety factor of a structure. 
With varying the structural design parameters, the above-mentioned process is repeated until the requirement of the object function is met. In the present study, the ULSDM is applied for the structural design of a box girder crane.

\section{Applied Example}

The target box girder crane structure made of SM490 was originally designed applying the ASWDM. The manufacturer of the crane structures now wants to use a high tensile steel of HSB500. To redesign the structure using the HSB 500 steel, the USLDM is now applied.

\subsection{Characteristics of Target Structures}

Fig. 3 shows the target box girder crane structures in real appearance of operation and three-dimensional CAD modelling where the box girder structures of the electric overhead traveling (EOT) system is the target structures to be designed in the present study. The crane system is composed of main and auxiliary girders together with hooks, trolleys and saddle girders. Fig. 4 shows the plan view of the target structure which is driven by the travelling truck at the ends of main and saddle girders. In the present study, the ultimate strength is analysed separately for the main girder and the combined auxiliary and saddle girders.

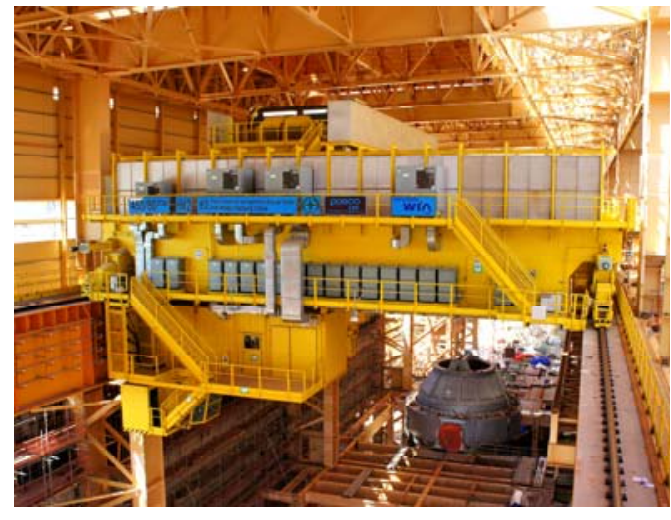

(a) Box girder crane in operation

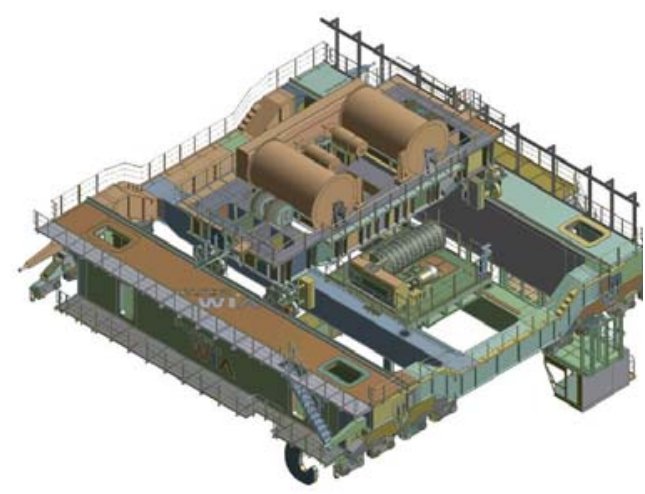

(b) 3-dimentional CAD model 
Fig. 3. The target box girder crane structures.

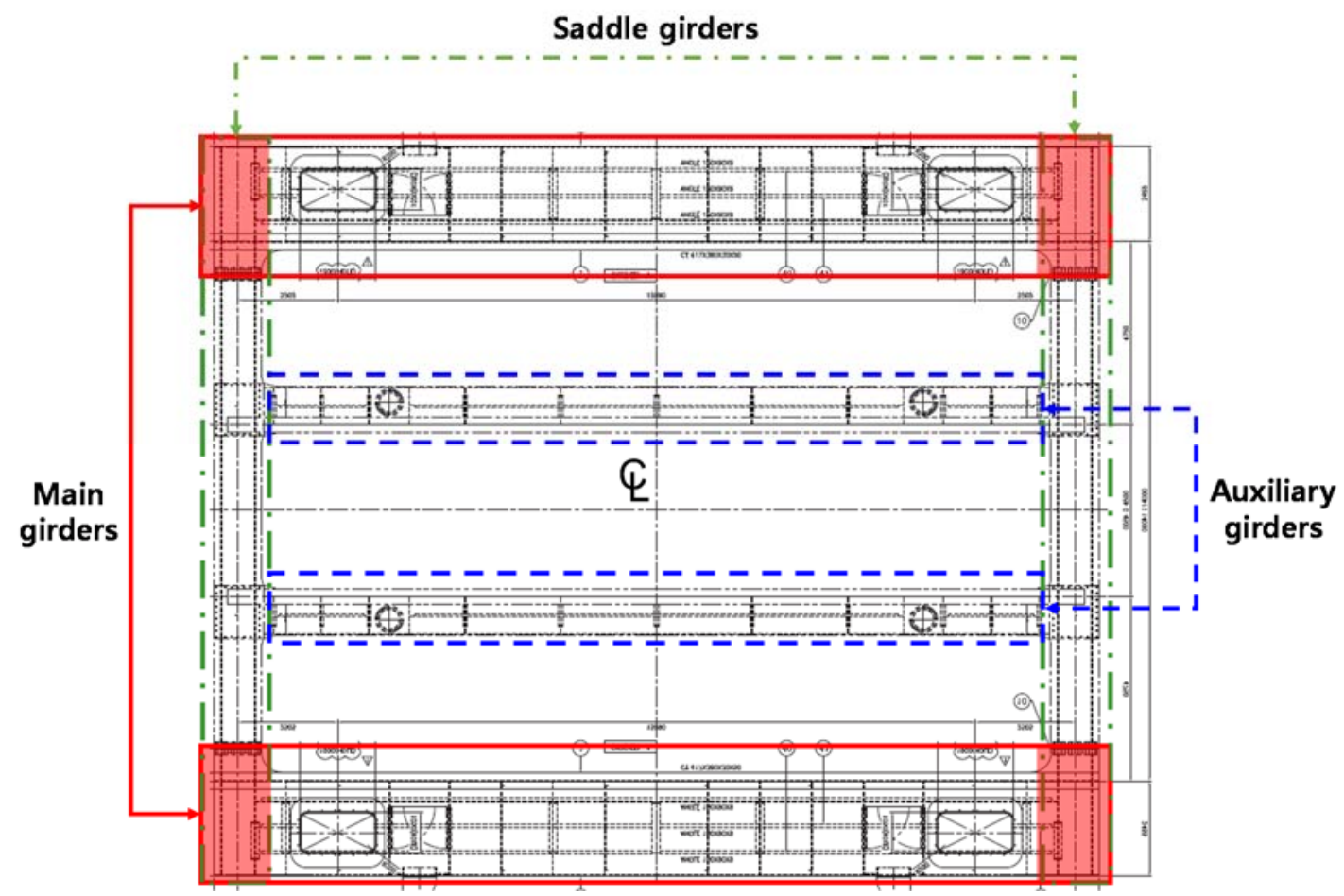

Fig. 4. Plan view of the target box girder crane structures.

UNIT: $(\mathrm{mm})$

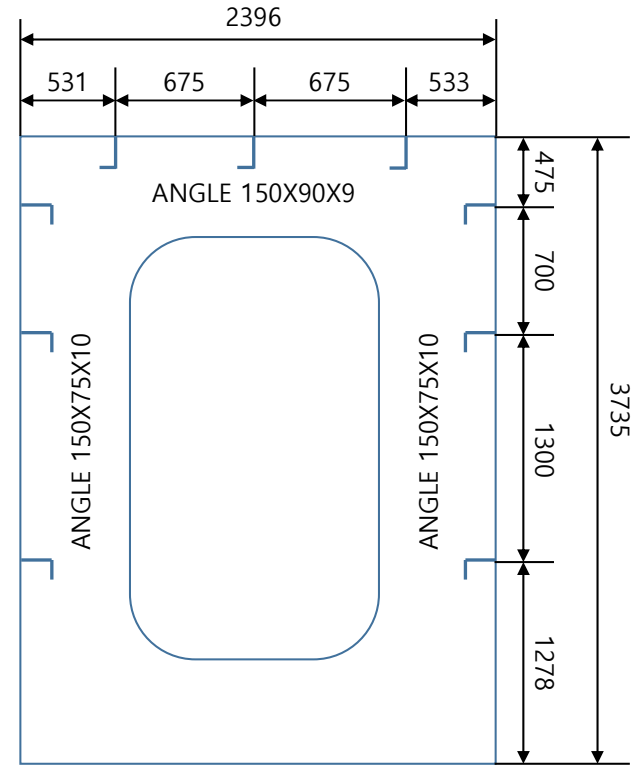

(a) Main girder
UNIT: (mm)

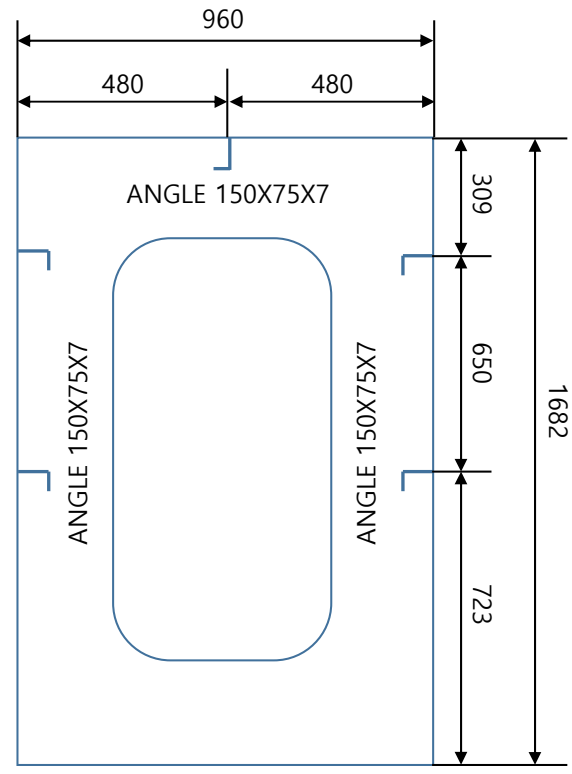

(b) Auxiliary girder

Fig. 5. Cross section of the main girders and auxiliary girders. 


\subsection{Objective Function and Limit State Criteria}

Table 1. Limit state criteria applied for the structural scantlings in the present study.

\begin{tabular}{ccl}
\hline $\begin{array}{c}\text { Constraint parameter } \\
\text { Ultimate strength } \\
\text { (maximum } \\
\begin{array}{c}\text { load-carrying } \\
\text { capacity) }\end{array}\end{array}$ & $\begin{array}{c}\text { Type of } \\
\text { limit states }\end{array}$ & \multicolumn{1}{c}{ Description } \\
Maximum deflection & SLS & $\begin{array}{l}\text { Ultimate strength of the structure with new } \\
\text { design at least should be maintained at the } \\
\text { equivalent ultimate strength level with the } \\
\text { existing design. }\end{array}$ \\
Matural frequency & SLS & $\begin{array}{l}\text { Maximum defection at design load level } \\
\text { should not exceed L/1000 [46]. } \\
\text { frequency for crane structure is } 1.7 \mathrm{~Hz}[46] .\end{array}$ \\
Plate thickness & SLS & $\begin{array}{l}\text { Minimum plate thickness is limited by } 9 \mathrm{~mm}, \\
\text { considering welding. }\end{array}$ \\
\hline
\end{tabular}

The objective of the structural optimization is to minimize the structural weight of the main and auxiliary girders, keeping the safety at a required level. Table 1 indicates the limit state criteria applied for the present design in association with the ULS and the SLS. The FLS was also considered but it will be reported in a separate paper.

\subsection{Nonlinear Finite Element Modelling}

In order to determine the ultimate strength of the target structures, the elastic plastic large deflection finite element method is applied using ANSYS computer program [47].

\subsubsection{Nonlinear Finite Element Models}

Fig. 6 shows the FE models of the target structures, where a half part of the combined auxiliary and saddle girders is taken as the extent of the analysis because of the symmetric condition with regard to the center line, although a full structure of the main girder is included in the FE model. 
In industry practice, stiffeners are often modelled by beam elements. However, beam element models for stiffeners may not give accurate computations in terms of local buckling, e.g., local web buckling and tripping, and plasticity. In this regard, only 4-noded plate-shell elements are used to model not only plating and stiffener webs but also stiffener flanges In order to ensure the mesh size, convergence studies for the main girder and auxiliary girder are performed by varying the element size. Figure 7 shows the results of the convergence studies in terms of ultimate strength and maximum deflection. It is obvious that a convergence is achieved at the element size of $50 \mathrm{~mm}$ where all element sizes are identical.

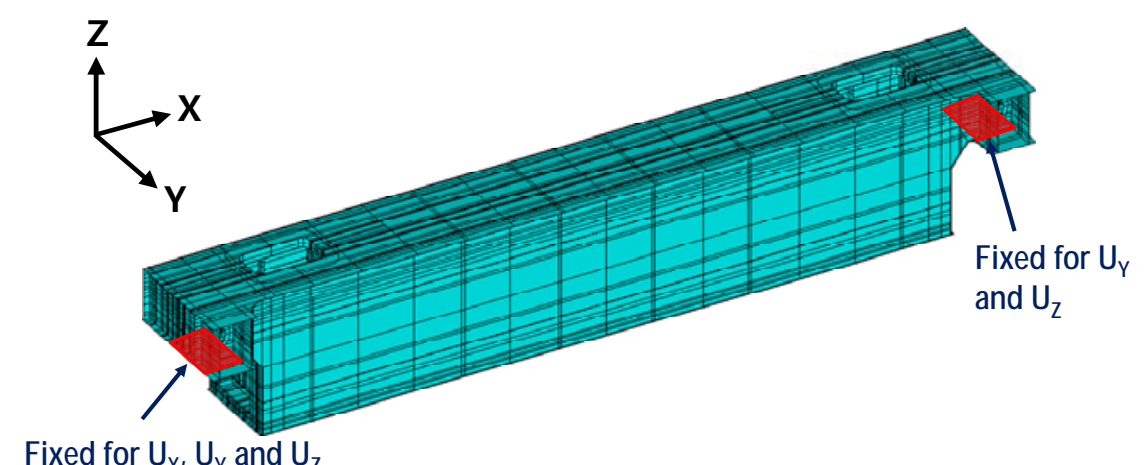

Fixed for $U_{X}, U_{Y}$ and $U_{Z}$

(a) The FE model of the main girder structures for a full part

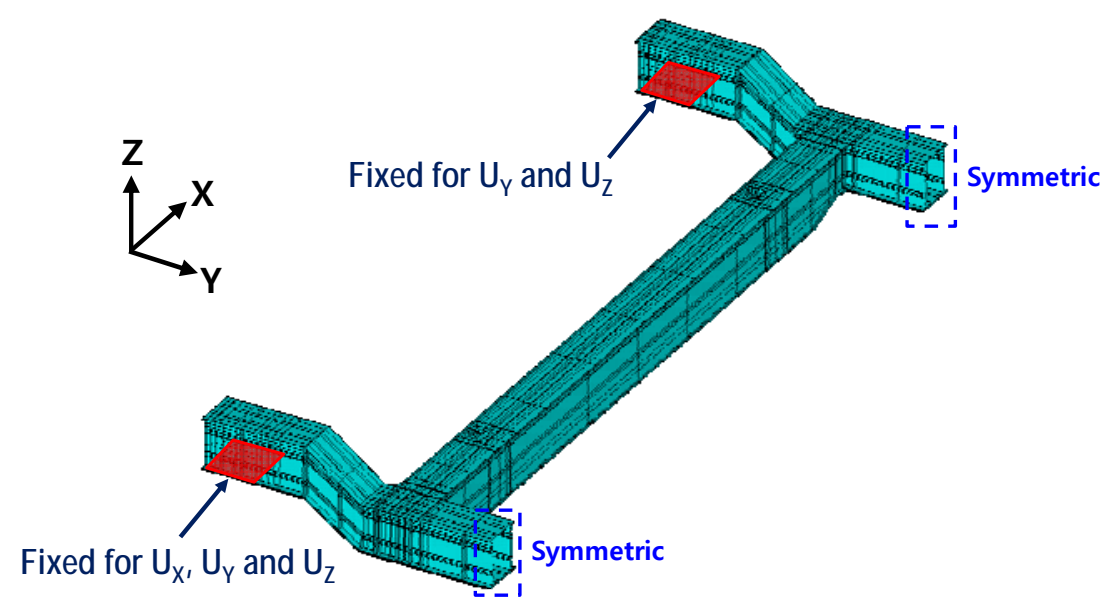

(b) The FE model of the combined auxiliary and saddle girder structures for a half part

Fig. 6. The nonlinear FE model with applied boundary conditions. 


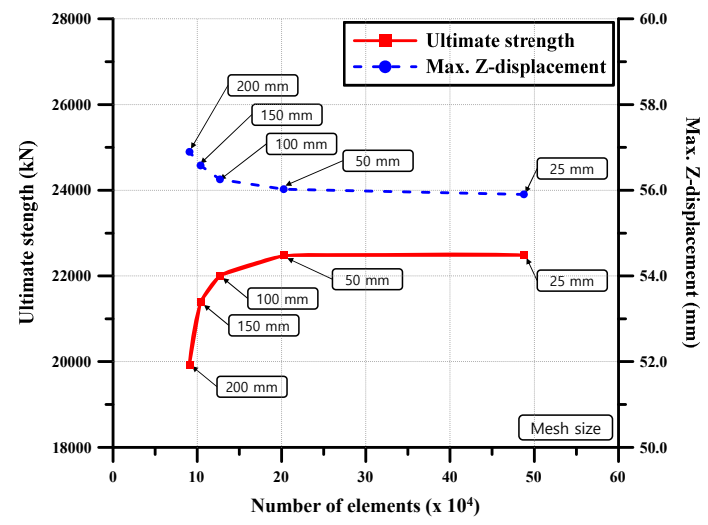

(a) Main girder

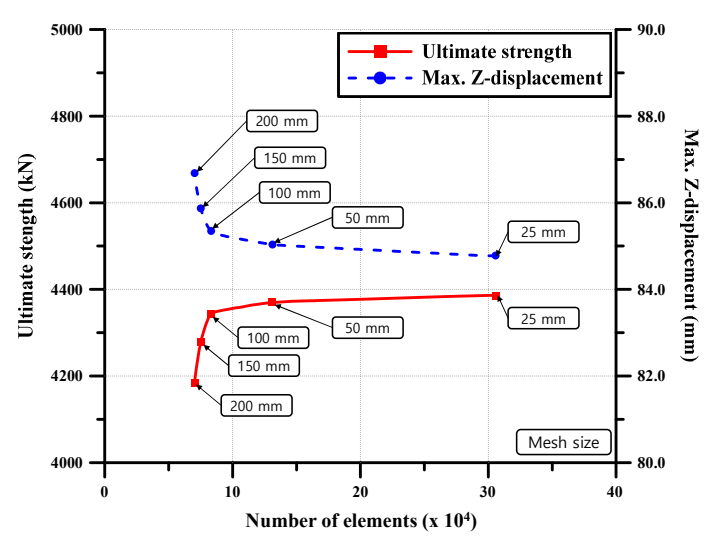

(a) Auxiliary girder

Fig. 7. The convergence study to determine the best element size using identical meshes.

\subsubsection{Boundary Conditions}

Fig. 6 presents the boundary conditions for the nonlinear finite element analysis. The crane structural system is considered to be simply supported at the ends because the main girder is supported on the travelling truck which is positioned on rigid rails. In this regard, the shaded areas with a rectangular shape shown in Fig. 5 are assigned by the corresponding boundary conditions. In the ANSYS code application, the boundary conditions with the "Coupling" option was adopted.

\subsubsection{Material Properties}

Table 2 indicates the material properties of existing SM490 steel and new HSB500 steel. In the present study, an elastic perfectly-plastic material model is applied without considering the strain-hardening effect.

Table 2. Material properties of SM490 steel and HSB500 steel.

\begin{tabular}{ccc}
\hline \multirow{2}{*}{ Material property } & Used material & New material \\
\cline { 2 - 3 } & SM490 steel & HSB500 steel \\
\hline Density, $\rho\left(\operatorname{ton} / \mathrm{m}^{3}\right)$ & 7.85 & 7.85
\end{tabular}


Young's modulus, E (GPa)

Poisson's ratio, $v$

Yield strength, $\sigma_{Y}(\mathrm{MPa})$

Ultimate tensile strength, $\sigma_{T}(\mathrm{MPa})$

\subsubsection{Loading Conditions}

The live loads from the trolley are transferred through the wheels to the box girder. In this study, two loading positions are considered according to the position of trolley. Figs. 8 and 9 present the loading positions which are considered to be the most severe loading scenarios in operation. Table 3 summarizes the structural weight of the main and auxiliary girders in the original design.

Table 3. Structural weight of the main and auxiliary girders in the original design.

\begin{tabular}{ccc}
\hline \multirow{2}{*}{ Category } & \multicolumn{2}{c}{ Magnitude (tonf) } \\
\cline { 2 - 3 } & Main girder & Auxiliary girder \\
\hline Girder weight & 54.66 & 14.35 \\
Attachment weight & 36.24 & 7.45 \\
Total self-weight (WM) & 90.90 & 21.80 \\
\hline
\end{tabular}

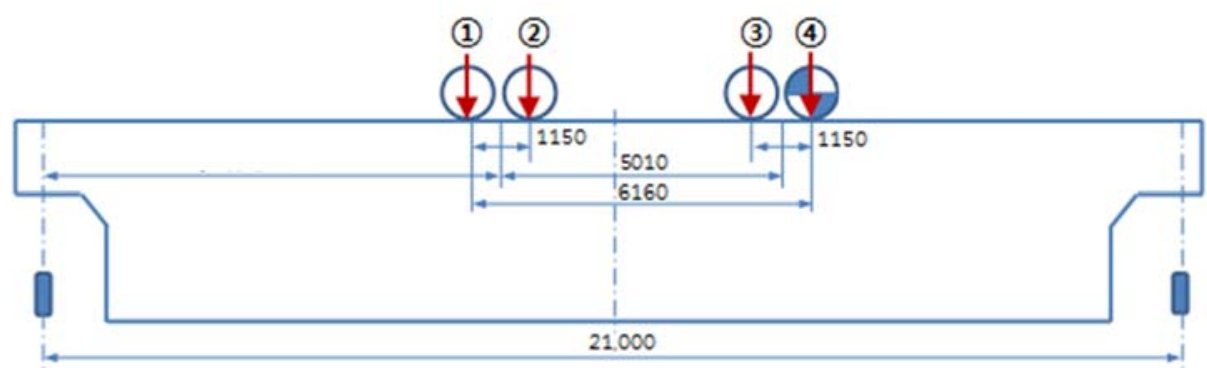

(a) Loading position 1: The trolley locates at mid span of the main girder 


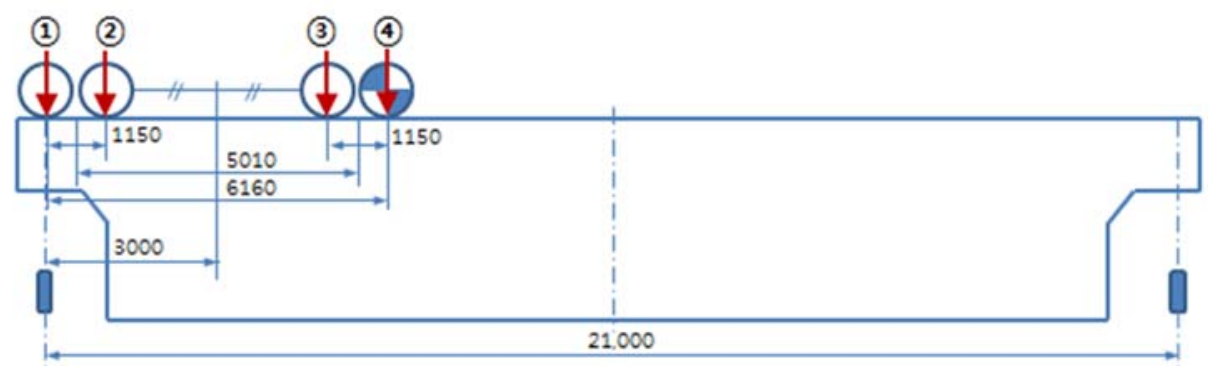

(b) Loading position 2: The trolley locates at end of the main girder

Fig. 8. Loading positions of the main girder considered in the FE analysis.

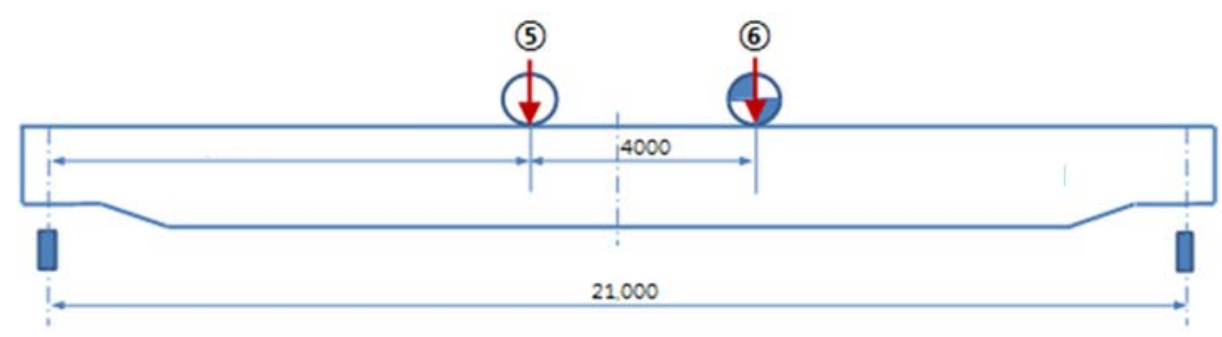

(a) Loading position 1: The trolley locates at mid span of the auxiliary girder

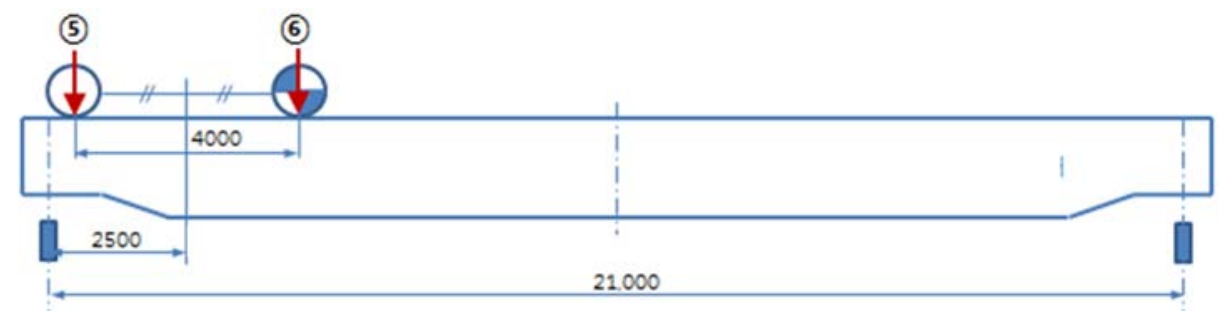

(b) Loading position 2: The trolley locates at end of the auxiliary girder

Fig. 9. Loading positions of the auxiliary girder considered for the present FE analysis.

The loads applied to the crane structure are classified into two categories. The first category embodies dead loads of built-in machinery and equipment, and the machinery-induced moment. In the second category, all loads transferred from the wheels of the trolley are included. The auxiliary girder does not facilitate machinery and equipment. Fig. 10 and Table 4 summarize the load cases for the main girder, while Fig. 11 and Table 5 present the load cases for the auxiliary girder. It is noted that the 
load cases have been decided by the design specification of the electronic overhead travelling crane as presented by AIST [48].

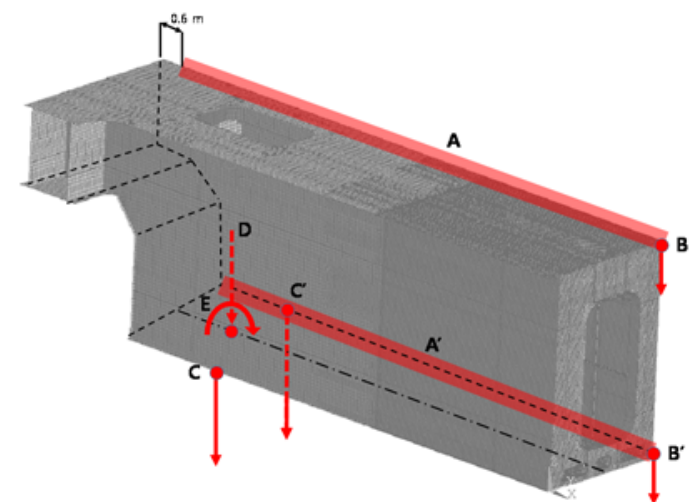

(a) Load case 1

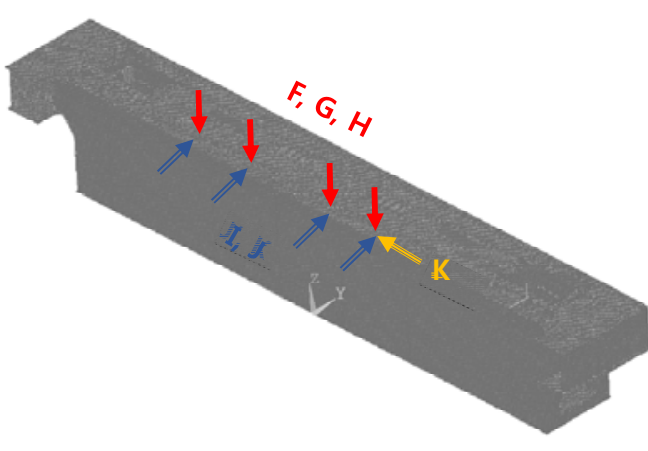

(b) Load case 2

Fig. 10. Presentation of the load cases for the main girder with the nomenclature indicated in Table 4.

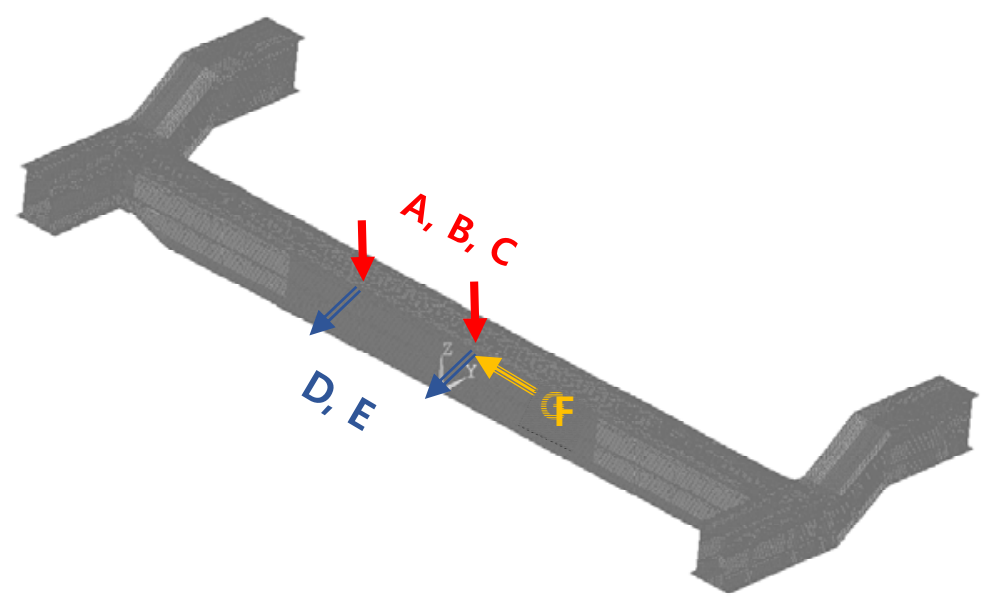

Fig. 11. Presentation of the load cases for the auxiliary girder with the nomenclature indicated in Table 5.

Table 4. The load cases for the main girder.

$\begin{array}{lll}\text { Case } & \text { Label Magnitude } & \text { Description } \\ \text { No. } & & \end{array}$




\begin{tabular}{|c|c|c|c|}
\hline- & $\begin{array}{l}- \\
-\end{array}$ & $\begin{array}{c}\text { Ref. Table } 2 \\
0.2 \times \mathrm{W}_{\mathrm{M}}\end{array}$ & $\begin{array}{l}\text { Self-weight } \\
\text { Girder inertia force }\end{array}$ \\
\hline \multirow{6}{*}{1} & $\mathrm{~A}$ & 0.495 tonf $/ \mathrm{m}$ & Upper walkway load \\
\hline & $A^{\prime}$ & 0.669 tonf $/ \mathrm{m}$ & Lower walkway load \\
\hline & $\mathrm{B}, \mathrm{B}$ ' & 0.227 tonf & Eccentric load \\
\hline & $\mathrm{C}, \mathrm{C}^{\prime}$ & 3.5 tonf & Cabin load \\
\hline & $\mathrm{D}$ & 3.2 tonf & Driving motor weight \\
\hline & $\mathrm{E}$ & 1.82 tonf-m & Motor-induced moment \\
\hline \multirow{6}{*}{2} & $\mathrm{~F}$ & 220 tonf & Dead load of trolley (DLT) \\
\hline & $\mathrm{G}$ & 450 tonf & Lifted load (LL) \\
\hline & $\mathrm{H}$ & $0.2 \times \mathrm{LL}$ & Vertical impact load \\
\hline & $\mathrm{I}$ & $0.2 \times\left(\mathrm{DL}_{\mathrm{T}}+\mathrm{LL}\right)$ & Bridging inertia force \\
\hline & $\mathrm{J}$ & $0.2 \times\left(\mathrm{DLT}_{\mathrm{T}}+\mathrm{LL}\right)$ & Skewing force \\
\hline & $\mathrm{K}$ & $0.15 \times\left(\mathrm{DLT}_{\mathrm{T}}+\mathrm{LL}\right)$ & Inertia force from drive (IFD) \\
\hline
\end{tabular}

Table 5. The load cases for the auxiliary girder

\begin{tabular}{|c|c|c|c|}
\hline $\begin{array}{c}\text { Case } \\
\text { No. }\end{array}$ & Label & Magnitude & Description \\
\hline \multirow{2}{*}{ - } & - & Ref. Table 2 & Self-weight \\
\hline & - & $0.2 \times \mathrm{W}_{\mathrm{A}}$ & Girder inertia force \\
\hline \multirow{6}{*}{1} & A & 49.0 tonf & Dead load of trolley $\left(\mathrm{DL}_{\mathrm{T}}\right)$ \\
\hline & $\mathrm{B}$ & 50 tonf & Lifted load (LL) \\
\hline & $\mathrm{C}$ & $0.2 \times \mathrm{LL}$ & Vertical impact load \\
\hline & $\mathrm{D}$ & $0.2 \times\left(\mathrm{DL}_{\mathrm{T}}+\mathrm{LL}\right)$ & Bridging inertia force from \\
\hline & $\mathrm{E}$ & $0.2 \times\left(\mathrm{DLT}_{\mathrm{T}}+\mathrm{LL}\right)$ & Skewing force \\
\hline & $\mathrm{F}$ & $0.15 \times\left(\mathrm{DL}_{\mathrm{T}}+\mathrm{LL}\right)$ & Inertia force from drive (IFD) \\
\hline
\end{tabular}

The design demand $D_{d}$ of the target structure can be defined considering the partial safety factors for loads as follows [49]: 


$$
D_{d}=\gamma_{d, c}\left(\gamma_{d, d} D L+\gamma_{d, l} L L\right)
$$

where $\gamma_{d, c}$ is the partial safety factor associated with the uncertainties of load combination, $\gamma_{d, d}$ is the partial safety factor associated with the uncertainties of dead loads, and $\gamma_{d, \ell}$ is the partial safety factor associated with the uncertainties of live loads. The partial safety factors are indicated in Table 6 .

Table 6 . The partial safety factors associated with the uncertainties of loads.

\begin{tabular}{ccc}
\hline Category & Symbol & Value \\
\hline Load combination factor & $\gamma_{d, c}$ & 1.2 \\
Dead load factor (for trolley, DLT) & $\gamma_{d, d}$ & 1.5 \\
Live load factor (LL) & $\gamma_{d, \ell}$ & 1.5 \\
\hline
\end{tabular}

\subsection{Results of the Nonlinear Finite Element Analysis}

Fig. 12 shows the results of the ultimate strength behaviour for the main girder with different loading positions, and Table 7 summarizes the safety margin of the main girder which is determined as the ratio of the ultimate strength to the design loads. Fig. 13 shows the results of the ultimate strength for the auxiliary girder structures with different loading positions where the structural scantlings are the same as the original design and Table 8 indicates the safety margin of the auxiliary girder.

It is obvious that the ultimate strengths of the main and axillary girders can be increased by using high tensile steel with the same structural scantlings as those of the original structure. This means that the structural scantlings can be reduced in the use of high tensile steel if the ultimate strength of the girder structures is kept at the similar level to the original design using the SM490 steel. 


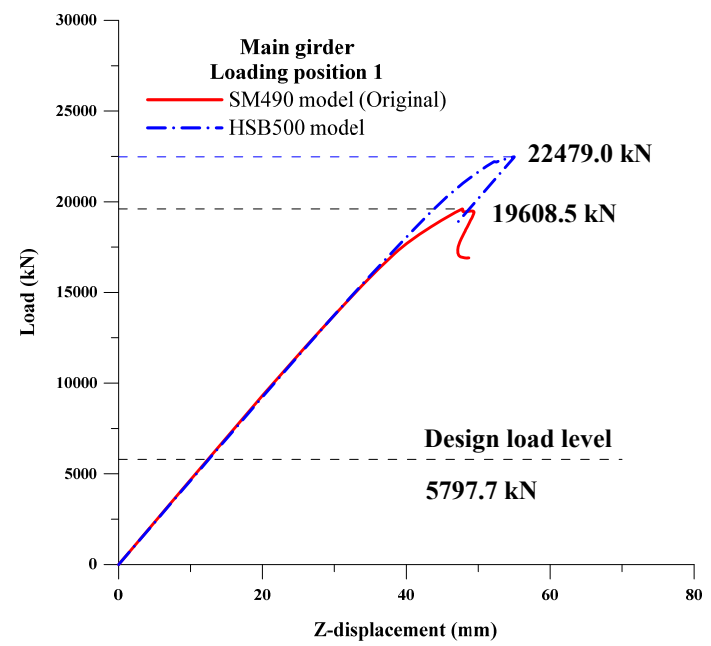

(a) Loading position 1

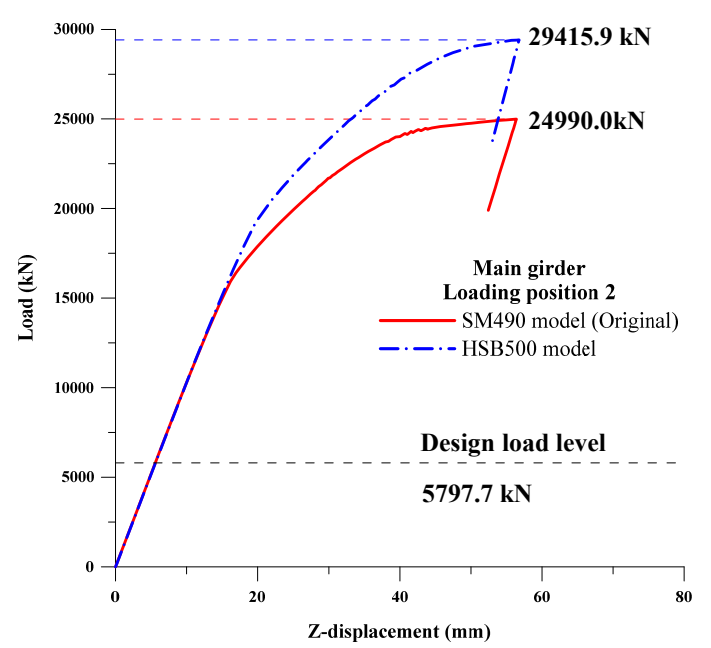

(a) Loading position 2

Fig. 12. Ultimate strength behaviour of the main girder with the structural scantlings in the original design.

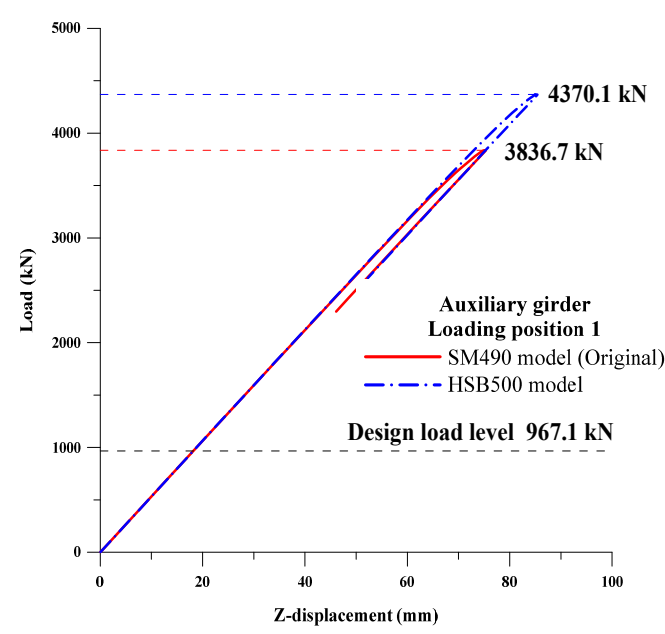

(a) Loading position 1

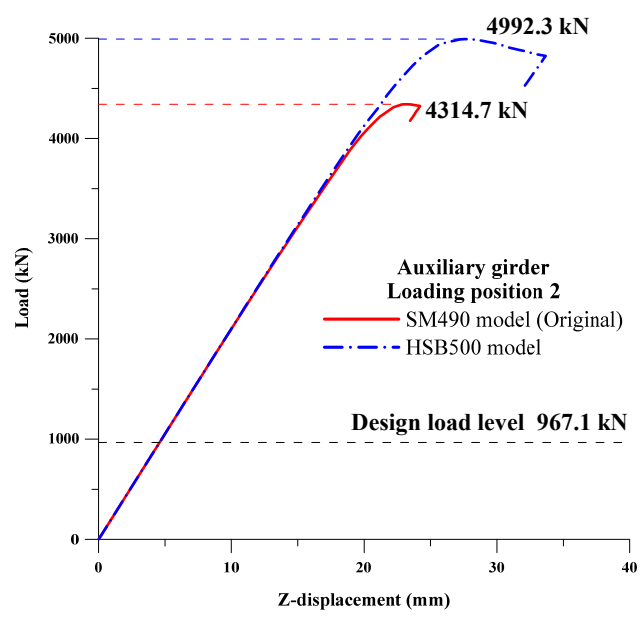

(a) Loading position 2

Fig. 13. Ultimate strength behaviour of the auxiliary girder with the structural scantlings in the original design.

Table 7. Safety margin of the main girder with the structural scantlings in the original design.

\begin{tabular}{cccc} 
& \multicolumn{2}{c}{ Safety margin } & $C_{d} / D_{d}$ \\
\cline { 2 - 3 } Loading position & B/A \\
\cline { 2 - 3 } & $\begin{array}{c}\text { Original (SM490) } \\
\text { design (A) }\end{array}$ & $\begin{array}{c}\text { New (HSB500) } \\
\text { design (B) }\end{array}$ & \\
\hline 1 & 3.38 & 3.88 & $14.8 \%$
\end{tabular}


Table 8. Safety margin of the auxiliary girder with the structural scantlings in the original design.

\begin{tabular}{cccc}
\hline \multirow{2}{*}{ Loading position } & \multicolumn{2}{c}{ Safety margin } & $C_{d} / D_{d}$ \\
\cline { 2 - 3 } & $\begin{array}{c}\text { Original (SM490) } \\
\text { design (A) }\end{array}$ & $\begin{array}{c}\text { New (HSB500) } \\
\text { design (B) }\end{array}$ & \\
\hline 1 & 3.97 & 4.52 & $13.9 \%$ \\
2 & 4.46 & 5.16 & $15.7 \%$ \\
\hline
\end{tabular}

\subsection{Structural Optimization}

It is now attempted to reduce the structural scantlings (plate thickness) using high tensile steel when the ultimate strength under the corresponding design loading conditions is kept at the similar level to the original design. As structural design variables, only the thickness of structural members is considered where the stiffener spacing is kept the same as the original design. The target plates were selected considering the efficiency of structural optimization. Figs. 14 and 15 show the target plates to be reduced for this purpose, while support members are unchanged in their scantlings.

The optimal thickness of target plates are modified following the case studies using trial and error method. The ultimate strength, maximum displacement, stress distributions, and local buckling strength are evaluated for each analysis case. Each analysis case is defined with reference to the structural effect of reduction of each plate thickness in previous analysis case. 


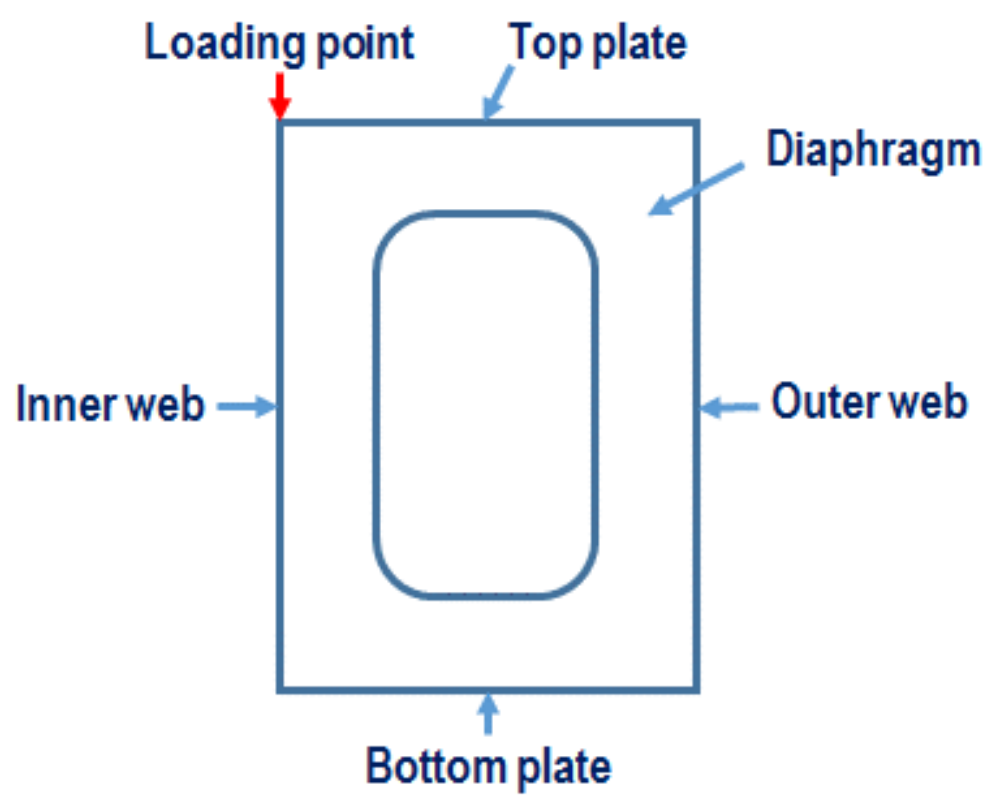

Fig. 14. Target plates to be reduced for the structural optimization (cross section).

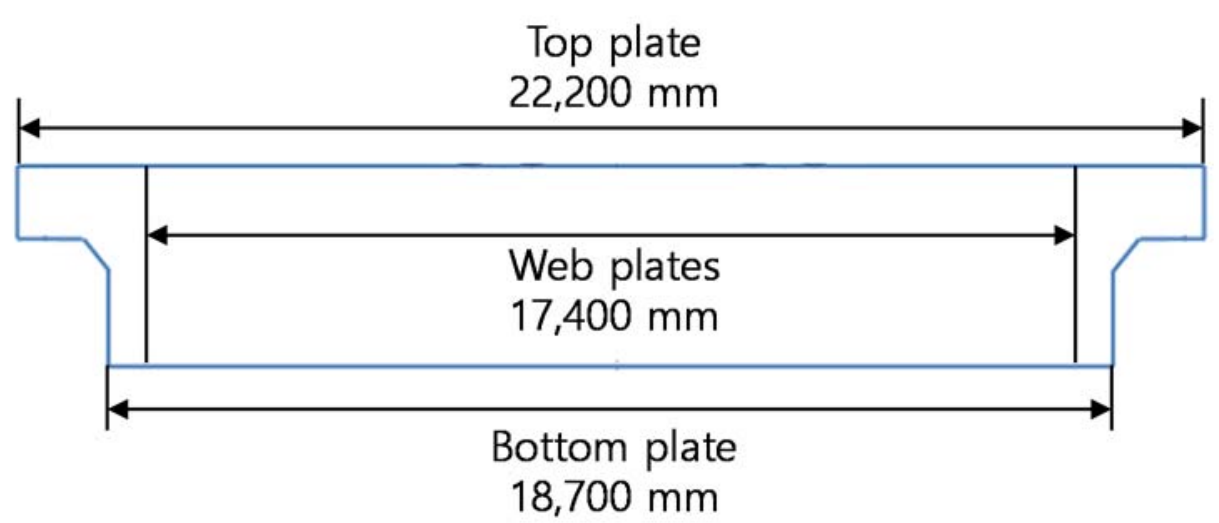

(a) Main girders

Top plate

$22,200 \mathrm{~mm}$

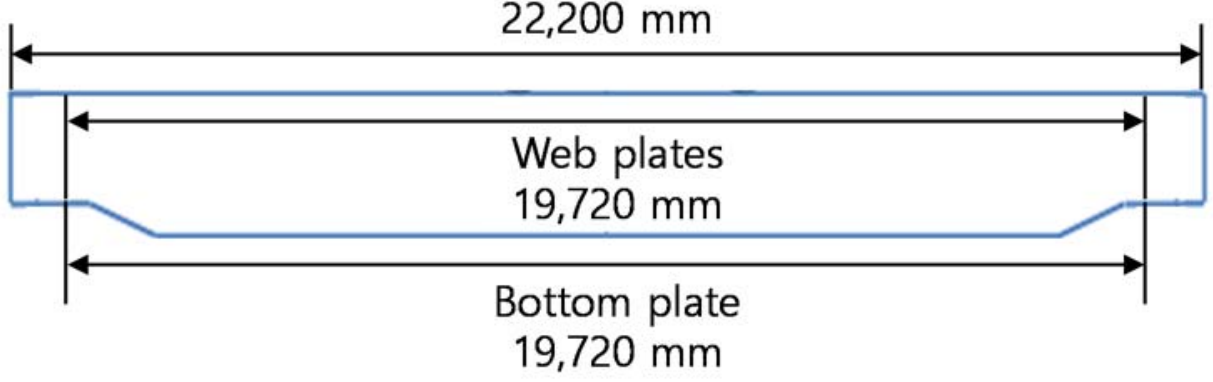

(b) Auxiliary girders 
Fig. 15. Target plates to be reduced for the structural optimization (profile view).

\subsubsection{Main Girder Structures}

A total of 7 case studies were undertaken as indicated in Table 9. The ultimate strength and the Z-displacement (deflection) were calculated for the cases as shown in Figs. 16 and 17. It is found that the main girder reaches the ULS after local bucking takes place in the inner web which is positioned below the trolley wheels followed by the extension of plasticity. It is considered that the collapse of the box girder crane system is triggered by the local buckling in the inner web, and thus a more detailed investigation is made in association with the local bucking strength of the inner web.

According to Table 9, the most successful achievement of the structural weight reduction is case 7 . However, it is recognized that the safety margin of the main girder structures for case 7 is only 1.89 in association with the local buckling in the inner web as shown in Fig. 18 and Table 10, implying that the inner web buckling occurs earlier. To take a greater safety margin value, therefore, the structural scantlings of case 6 are selected in the present study as the final design of the main girder structures using high tensile steel. Fig. 19 shows the von-Mises stress distribution of the final design at ultimate limit state. 
Table 9. Case studies for reducing the plate thickness of the main girder structures.

\begin{tabular}{|c|c|c|c|c|c|c|c|}
\hline \multirow[b]{2}{*}{ Case } & \multicolumn{2}{|c|}{ Weight (ton) } & \multicolumn{5}{|c|}{ Plate thickness (mm) } \\
\hline & Weight & Reduction & Top & Bottom & $\begin{array}{l}\text { Inner } \\
\text { web }\end{array}$ & $\begin{array}{l}\text { Outer } \\
\text { web }\end{array}$ & $\begin{array}{l}\text { Diaph-r } \\
\text { agm }\end{array}$ \\
\hline Original & 54.66 & 0 & 14 & 16 & 16 & 12 & 14 \\
\hline Case 1 & 50.84 & $\begin{array}{c}3.82 \\
(-7.0 \%)\end{array}$ & $14(-0)$ & $12(-4)$ & $14(-2)$ & $10(-2)$ & $12(-2)$ \\
\hline Case 2 & 49.75 & $\begin{array}{c}4.91 \\
(-9.0 \%)\end{array}$ & $14(-0)$ & $12(-4)$ & $13(-3)$ & $10(-2)$ & $10(-4)$ \\
\hline Case 3 & 49.38 & $\begin{array}{c}5.28 \\
(-9.7 \%)\end{array}$ & $14(-0)$ & $11(-5)$ & $13(-3)$ & $10(-2)$ & $10(-4)$ \\
\hline Case 4 & 49.34 & $\begin{array}{c}5.32 \\
(-9.7 \%)\end{array}$ & $14(-0)$ & $12(-4)$ & $13(-3)$ & $9(-3)$ & $10(-4)$ \\
\hline Case 5 & 50.16 & $\begin{array}{c}4.48 \\
(-8.2 \%)\end{array}$ & $14(-0)$ & $12(-4)$ & $14(-2)$ & $10(-2)$ & $10(-4)$ \\
\hline Case 6 & 49.06 & $\begin{array}{c}5.60 \\
(-10.2 \%)\end{array}$ & $14(-0)$ & $11(-5)$ & $14(-2)$ & $9(-3)$ & $9(-5)$ \\
\hline Case 7 & 47.42 & $\begin{array}{c}7.24 \\
(-13.3 \%) \\
\end{array}$ & $11(-3)$ & $11(-5)$ & $14(-2)$ & $9(-3)$ & $9(-5)$ \\
\hline
\end{tabular}

Note: The values in the parenthesis indicate the reduced thickness. 


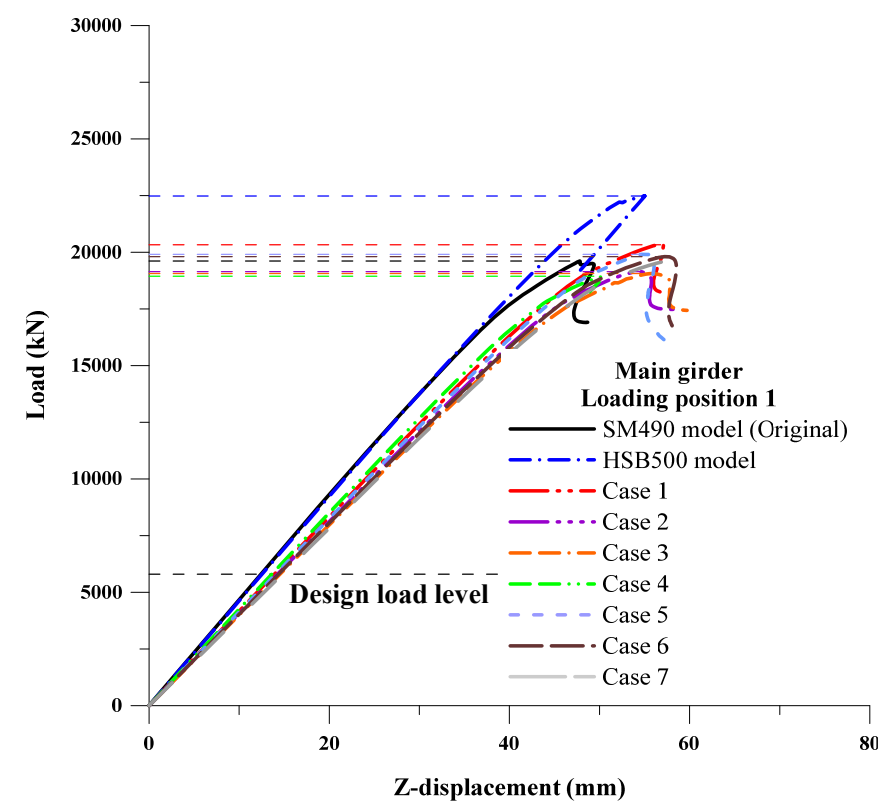

(a) Ultimate strength behaviour

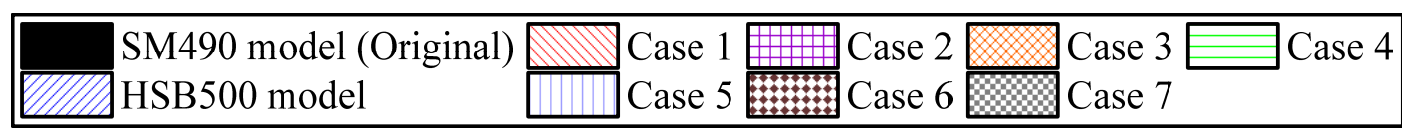

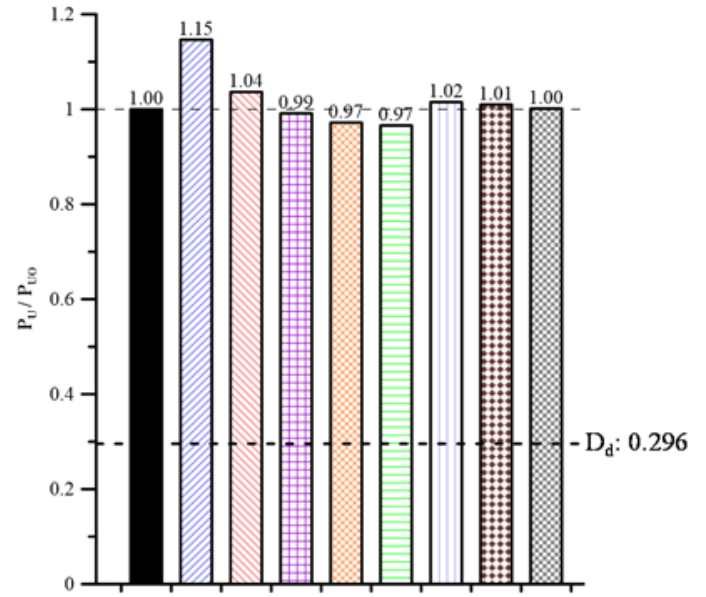

(b) Ultimate strength

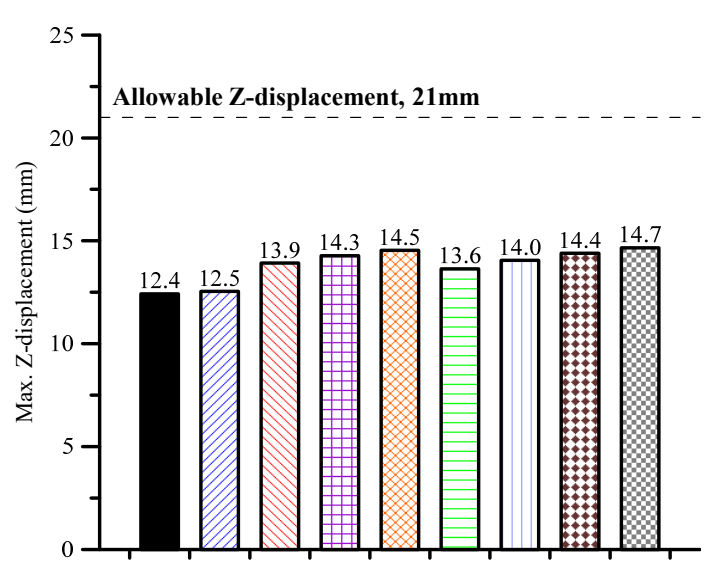

(c) Z-displacement at the design load level

Fig. 16. The results of the ultimate strength computations for the main girder structures at loading position 1 . 


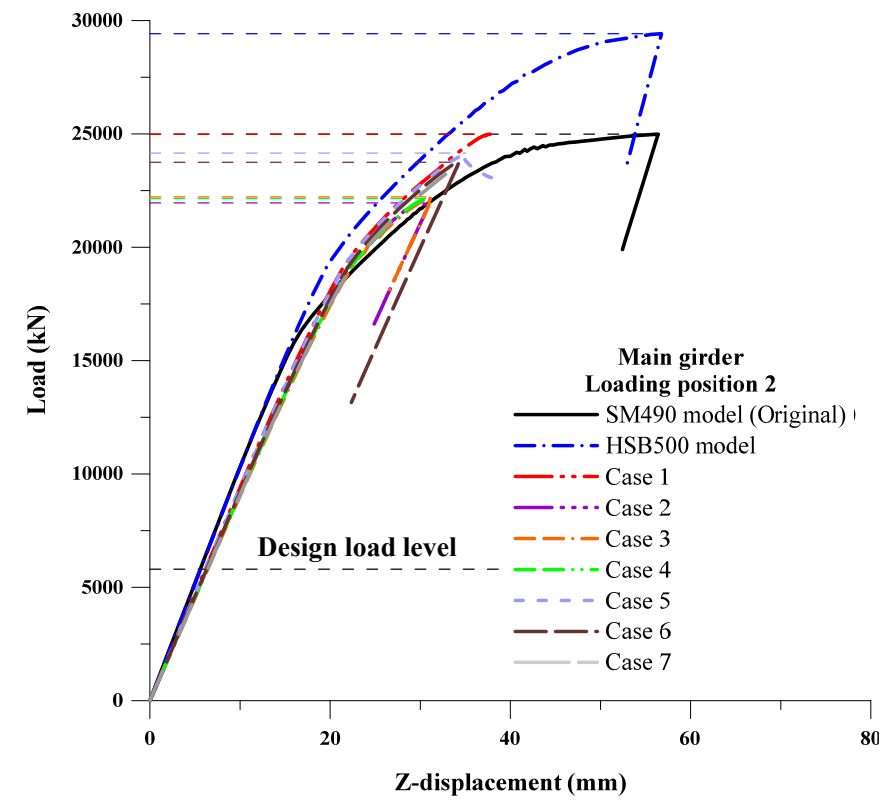

(a) Ultimate strength behaviour

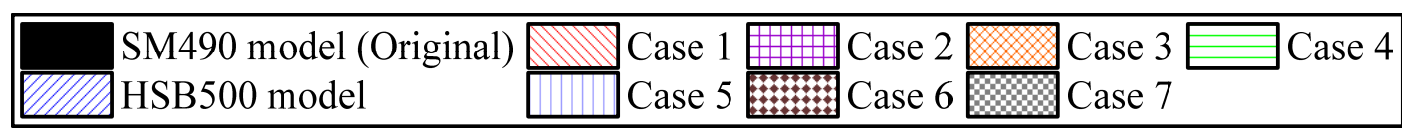

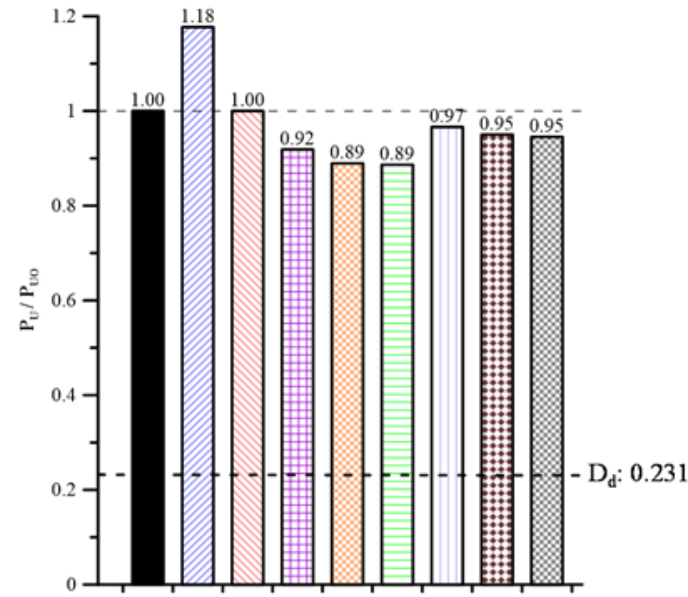

(b) Ultimate strength

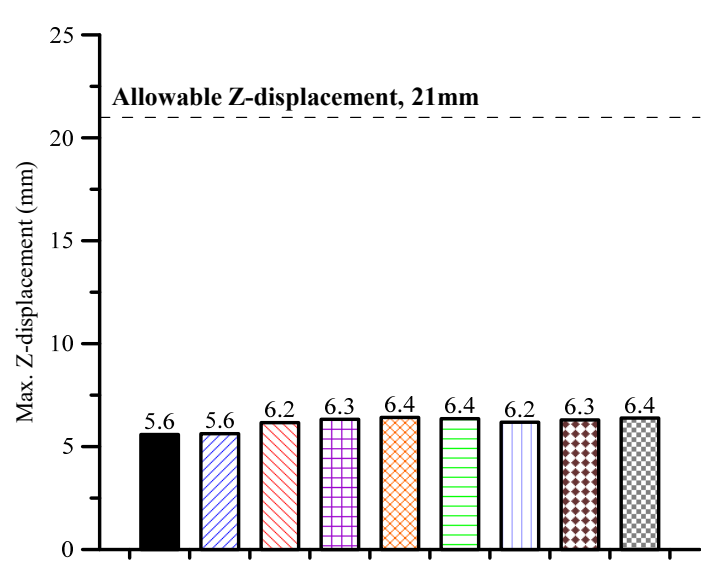

(c) Z-displacement at the design load level

Fig. 17. The results of the ultimate strength computations for the main girder structures at loading position 2 . 


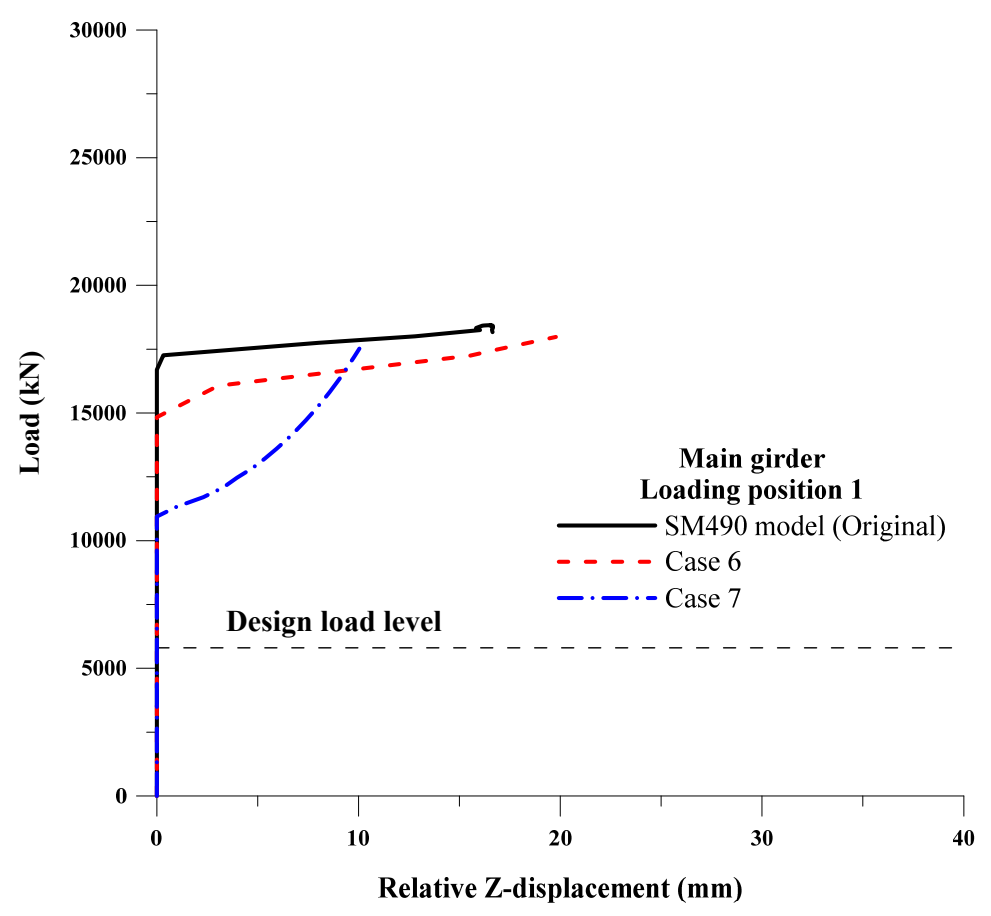

Fig. 18. Local buckling strength of the inner web of the main girder structures.

Table 10. Local buckling strength checks of the inner web of the main girder structures.

\begin{tabular}{cccc}
\hline Case & $\begin{array}{c}\text { Local buckling } \\
\text { strength }(\mathrm{kN})\end{array}$ & $\begin{array}{c}\text { Rate, divided by } \\
\text { original design }\end{array}$ & $\begin{array}{c}\text { Safety margin } \\
\text { for local bucking }\end{array}$ \\
\hline Original & 16693.14 & 1.00 & 2.88 \\
Case 6 & 14839.61 & 0.87 & 2.56 \\
Case 7 & 10941.57 & 0.64 & 1.89 \\
\hline
\end{tabular}

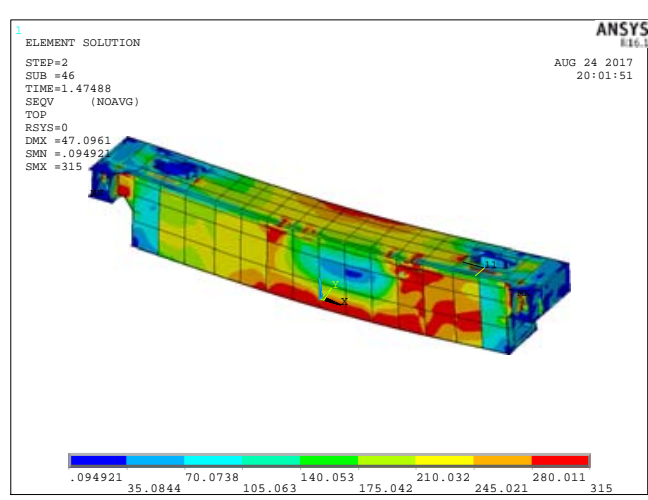

(a) Original design at loading position 1

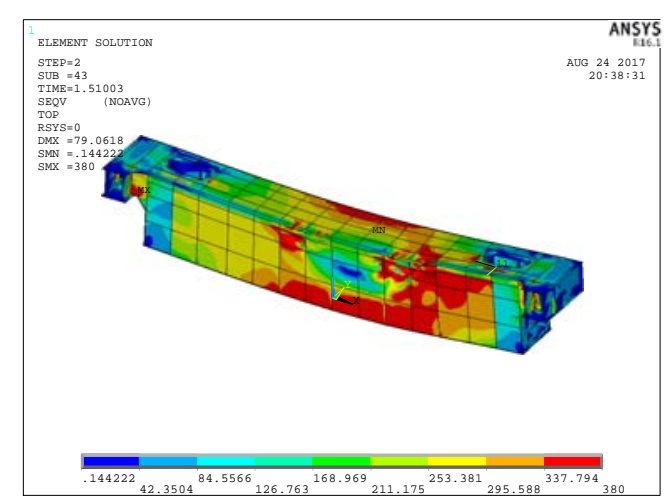

(b) Case 6 at loading position 1 


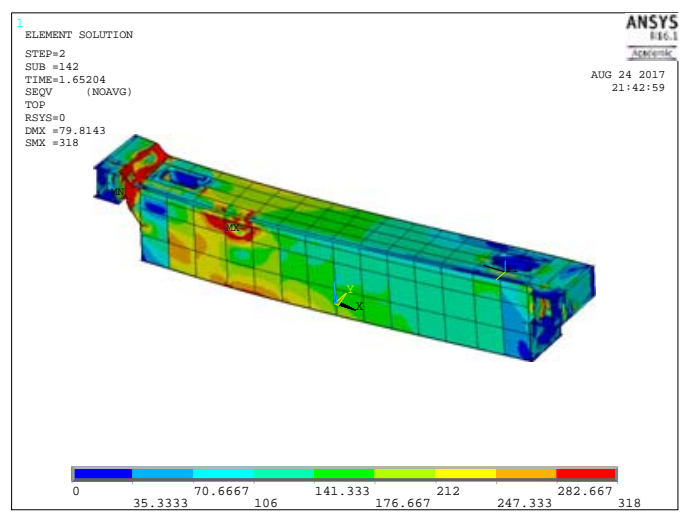

(c) Original design at loading position 2

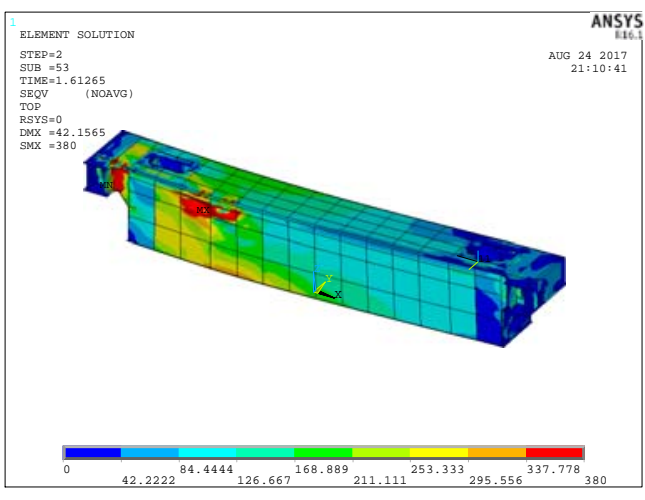

(d) Case 6 at loading position 2

Fig. 19. von-Mises stress distribution of the main girder at ultimate limit state.

\subsubsection{Auxiliary Girder Structures}

A total of 6 case studies were undertaken to reduce the structural scantlings as indicted in Table 11. Figs. 20 and 10 show the results of the ultimate strength computations. It is found that the auxiliary girder structures also reach the ULS after local bucking takes place in the inner web which is positioned below the trolley wheels. The local bucking strength of the inner web is also checked for each of the analysis cases. 
Table 11. Case studies for reducing the plate thickness of the auxiliary girder structures.

\begin{tabular}{|c|c|c|c|c|c|c|}
\hline \multirow[b]{2}{*}{ Case } & \multicolumn{2}{|c|}{ Weight (ton) } & \multicolumn{4}{|c|}{ Plate thickness (mm) } \\
\hline & Weight & Reduction & Top & Bottom & Inner web & $\begin{array}{l}\text { Outer } \\
\text { web }\end{array}$ \\
\hline Original & 14.35 & 0 & 18 & 18 & 10 & 10 \\
\hline Case1 & 13.20 & $\begin{array}{c}1.15 \\
(-8.0 \%)\end{array}$ & $18(-0)$ & $11(-7)$ & $10(-0)$ & $10(-0)$ \\
\hline Case2 & 12.56 & $\begin{array}{c}1.79 \\
(-12.4 \%)\end{array}$ & $18(-0)$ & $10(-8)$ & $9(-1)$ & $9(-1)$ \\
\hline Case3 & 13.39 & $\begin{array}{c}0.96 \\
(-6.7 \%)\end{array}$ & $18(-0)$ & $14(-4)$ & $9(-1)$ & $9(-1)$ \\
\hline Case4 & 13.06 & $\begin{array}{c}1.29 \\
(-9.0 \%)\end{array}$ & $18(-0)$ & $13(-5)$ & $9(-1)$ & $9(-1)$ \\
\hline Case 5 & 12.90 & $\begin{array}{c}1.45 \\
(-10.2 \%)\end{array}$ & $18(-0)$ & $12(-6)$ & $9(-1)$ & $9(-1)$ \\
\hline Case $6^{*}$ & 12.79 & $\begin{array}{c}1.56 \\
(-10.8 \%)\end{array}$ & $11(-7)$ & $11(-7)$ & $9(-1)$ & $9(-1)$ \\
\hline
\end{tabular}

*Case 6, Girder height $1950 \mathrm{~mm}(+250 \mathrm{~mm})$

Note: The values in the parenthesis indicate the reduced thickness.

In case of the auxiliary girder, the degradation of the bending rigidity caused by a reduction of the plate thickness makes it difficult to satisfy the design constraint associated with the defection. In order to secure the bending rigidity, the most economical way is to increase the web height of the girder. Therefore, the web height of the auxiliary girder is changed based on following conditions:

- To keep the bending rigidity at the same level of the existing design

- To meet the limiting condition on the maximum web height of $2050 \mathrm{~mm}$ associated with structural clearance in operation

In order to obtain the best web height, the moment of inertia of the box girder is investigated with varying the plate thickness and the web height as shown in Fig. 22. 
With consideration of the bending rigidity and the clearance, case 6 is selected as the best design as indicted in Table 11. The web height of case 6 increased by $250 \mathrm{~mm}$, i.e., from $1700 \mathrm{~mm}$ in the original design to $1950 \mathrm{~mm}$ in the new design.

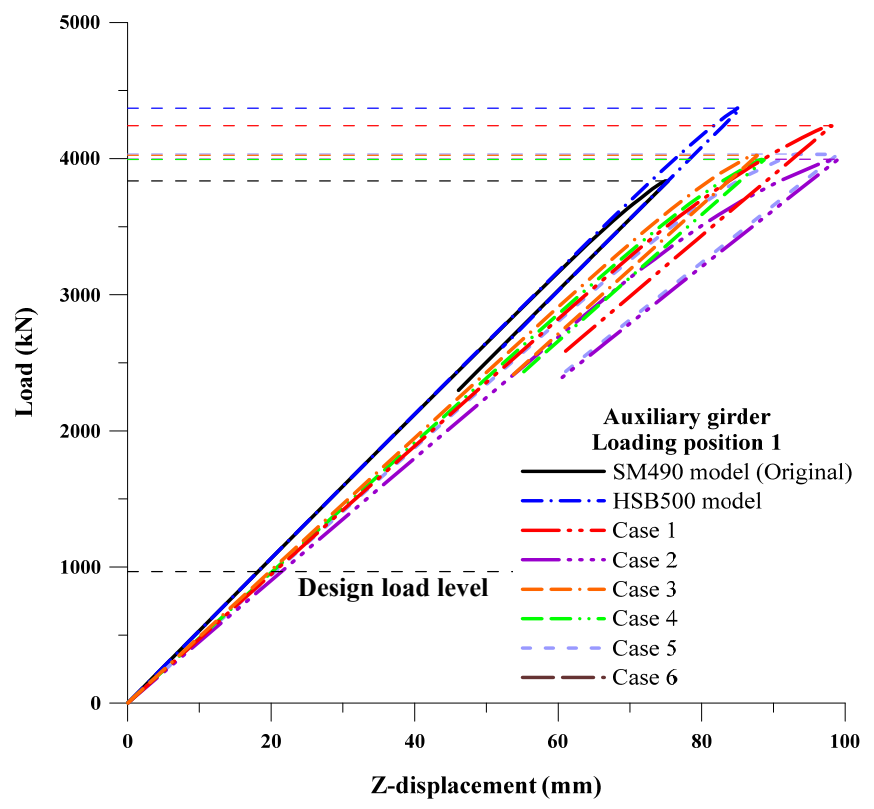

(a) Ultimate strength behaviour

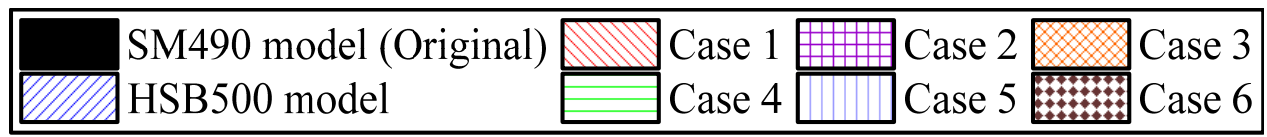

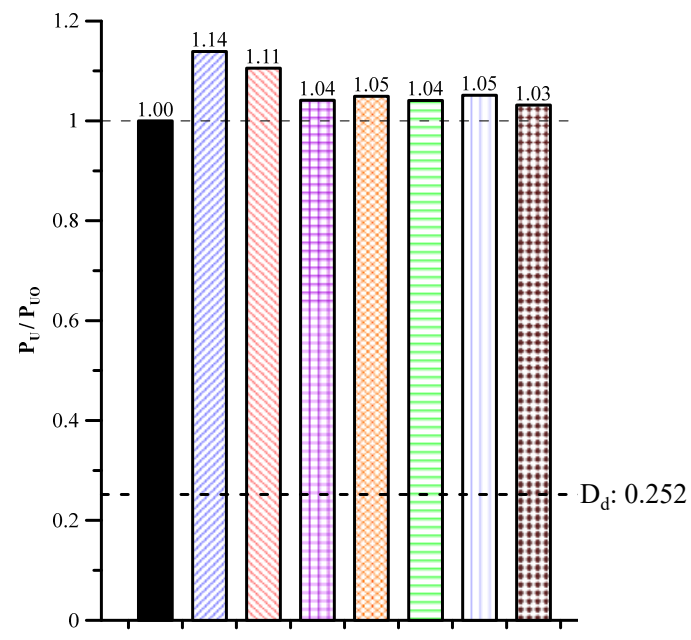

(b) Ultimate strength

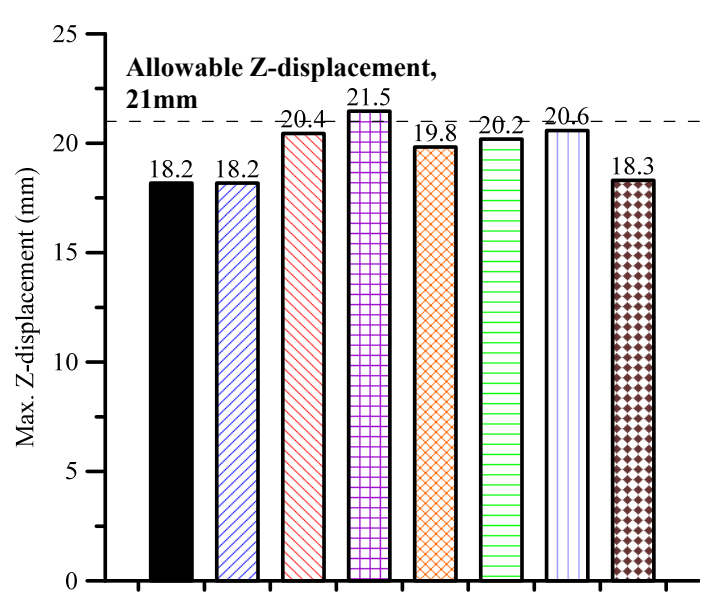

(c) Z-displacement at the design load level

Fig. 20. The results of the ultimate strength computations for the auxiliary girder structures at loading position 1. 


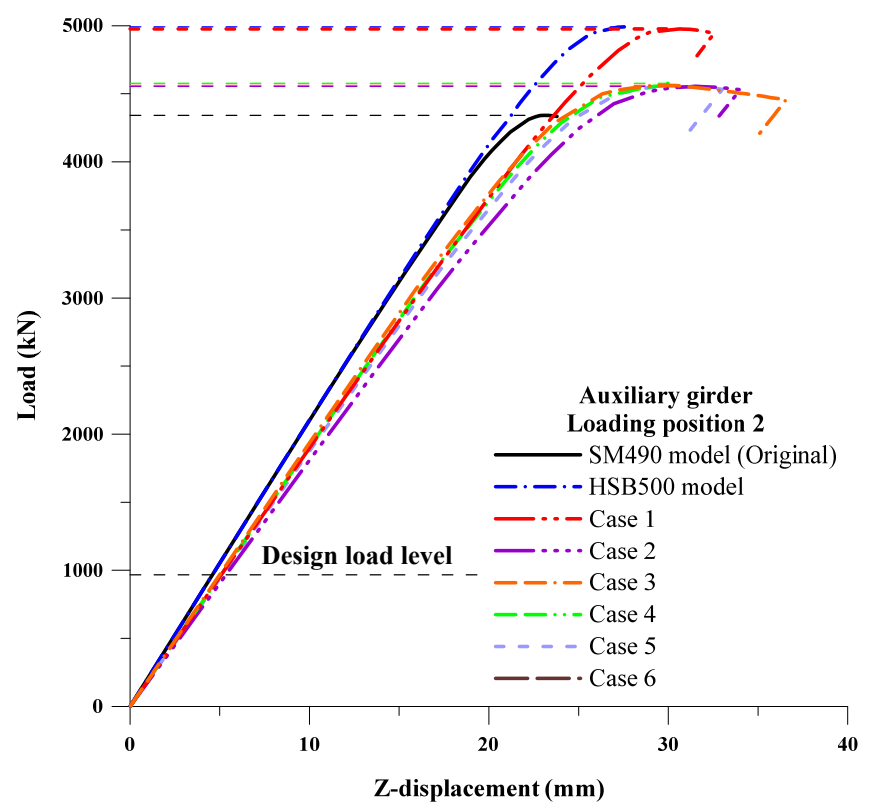

(a) Ultimate strength behaviour

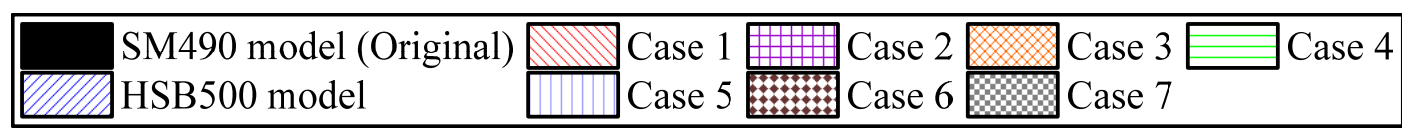

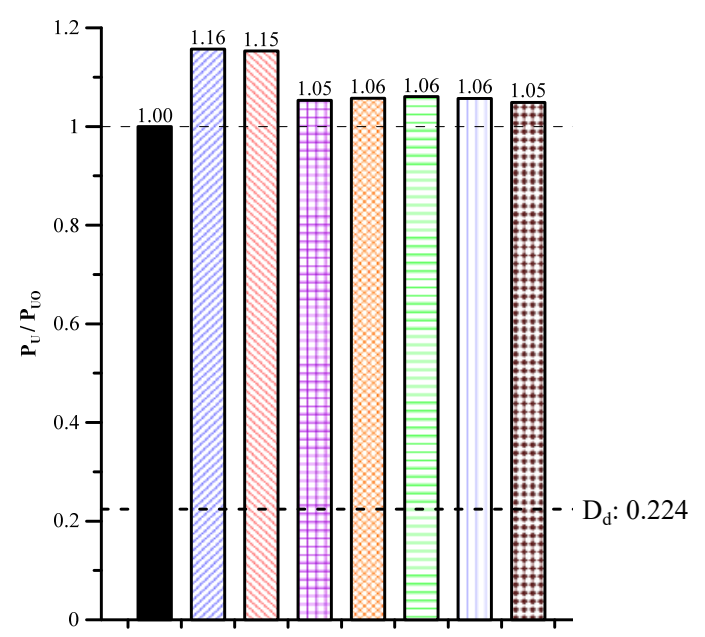

(b) Ultimate strength

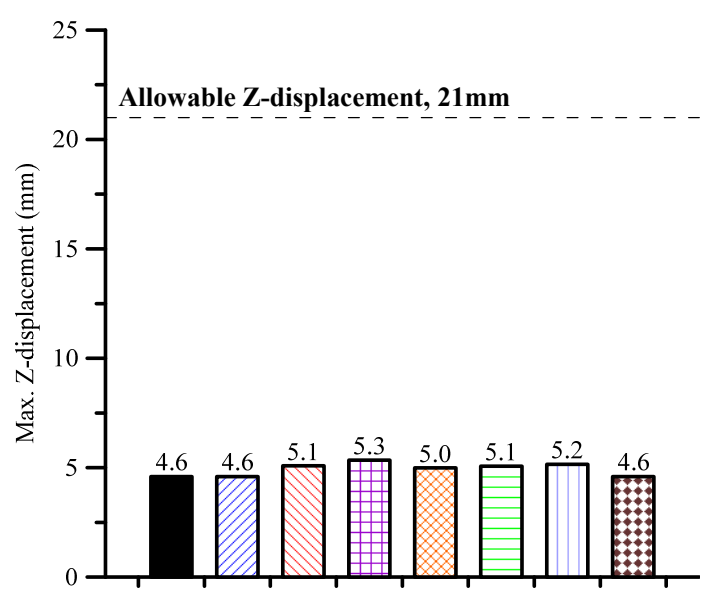

(c) Z-displacement at design load level

Fig. 21. The results of the ultimate strength computations for the auxiliary girder structures at loading position 2 . 


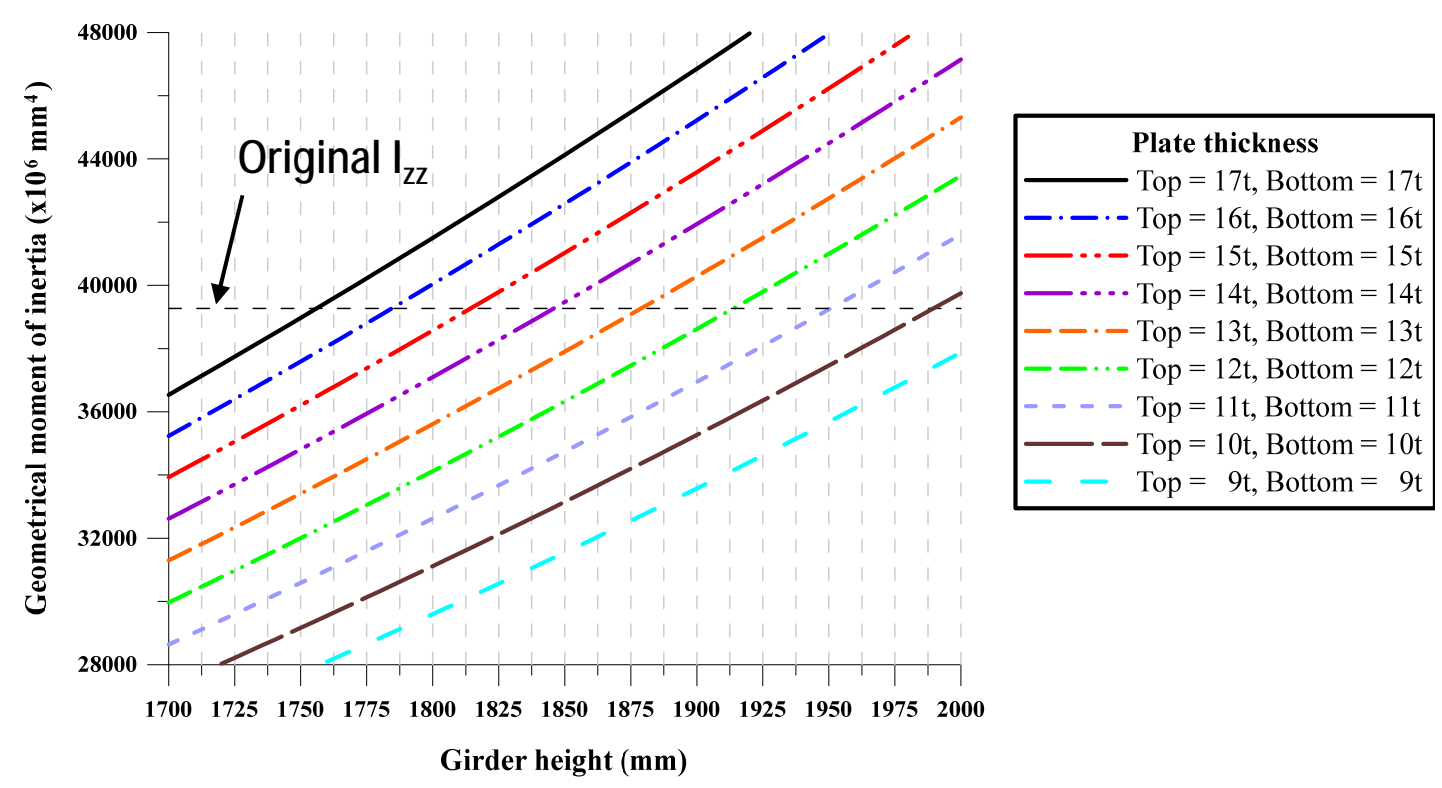

Fig. 22. Variation of the moment of inertia with varying the plate thickness and the web height.

The safety margin of the new design of case 6 is 2.58 as shown in Fig. 23 and Table 12. Fig. 24 shows the von-Mises stress distribution of the final design of the auxiliary box girder crane structures at ultimate limit state.

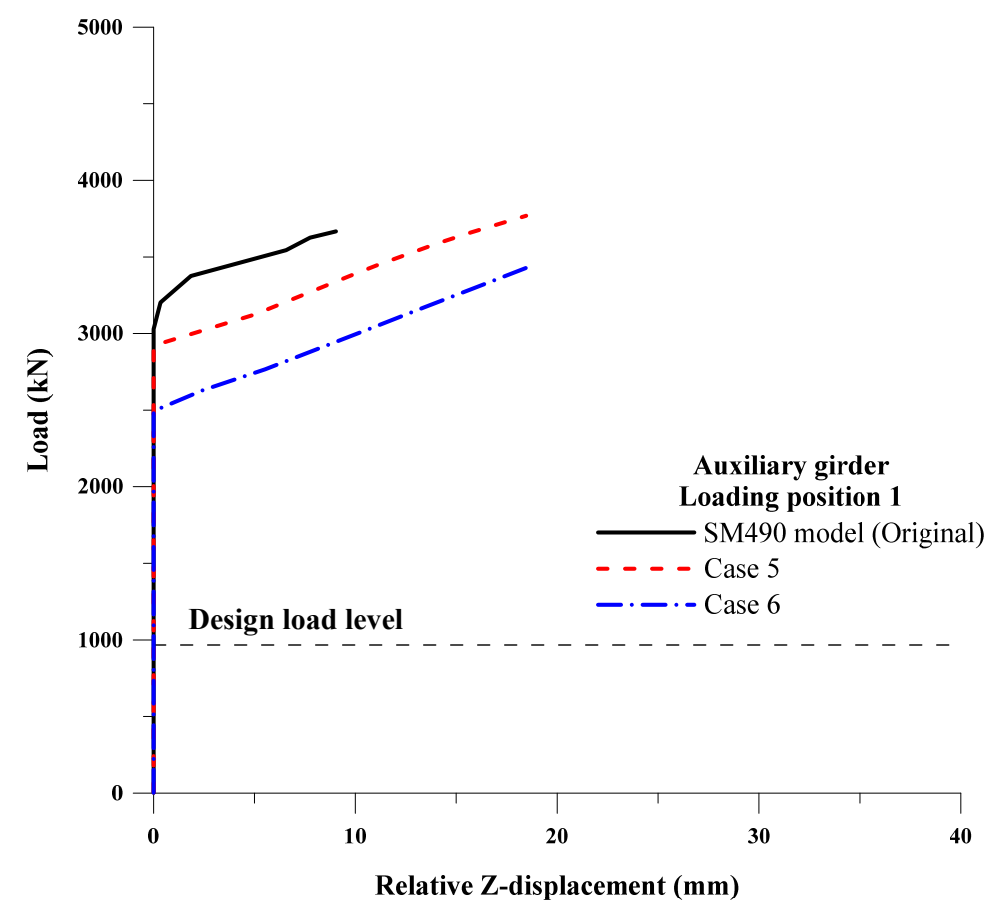

Fig. 23. Local buckling strength of the inner web in the auxiliary girder structures. 
Table 12. Local buckling strength checks of the inner web in the auxiliary girder structures.

\begin{tabular}{cccc}
\hline Case & $\begin{array}{c}\text { Local buckling } \\
\text { strength }(\mathrm{kN})\end{array}$ & $\begin{array}{c}\text { Rate, divided by } \\
\text { original design }\end{array}$ & $\begin{array}{c}\text { Safety margin } \\
\text { for local bucking }\end{array}$ \\
\hline Original & 3202.91 & 1.00 & 3.31 \\
Case 5 & 2921.20 & 0.91 & 3.02 \\
Case 6 & 2494.52 & 0.78 & 2.58 \\
\hline
\end{tabular}

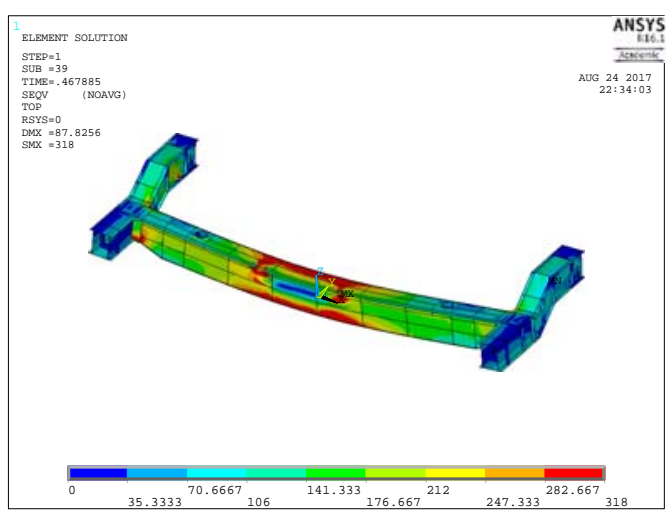

(a) Original design at loading position 1

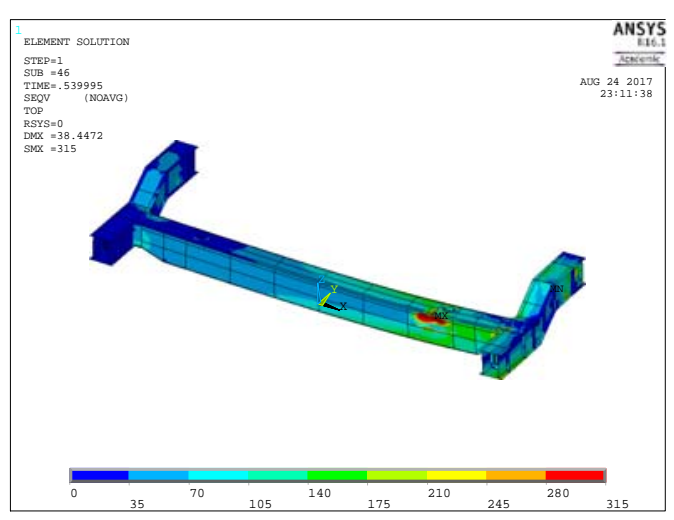

(c) Original design at loading position 2

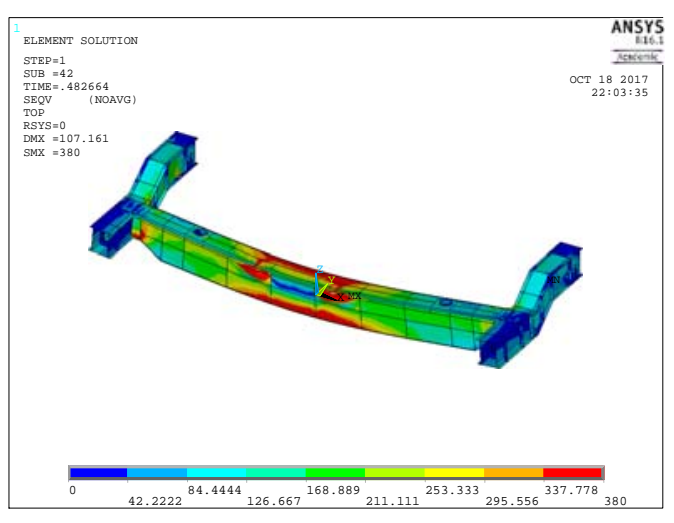

(b) Case 6 at loading position 1

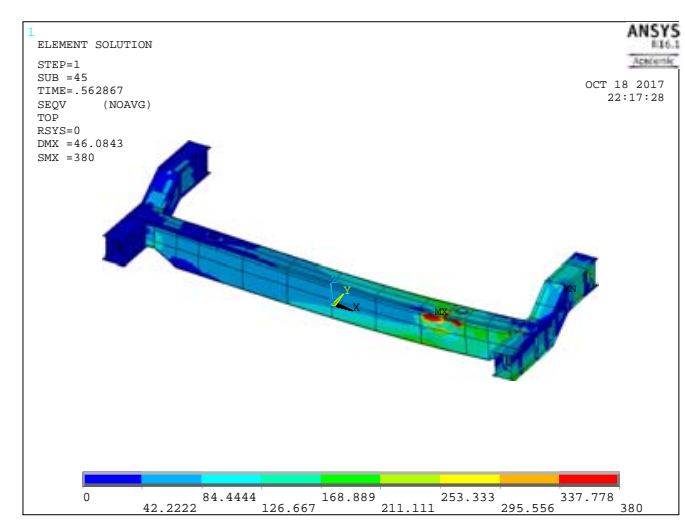

(d) Case 6 at loading position 2

Fig. 24. von-Mises stress distribution of the auxiliary box girder crane structures at ultimate limit state. 


\subsection{Eigenvalue Analysis}

In order to calculate the natural frequencies in terms of the SLS criteria, the eigenvalue analysis is carried out. The minimum requirement of natural frequencies is $1.7 \mathrm{~Hz}$ in association with the comfort of an operator and the proper functioning of crane structures [46]. The final designs of the main and auxiliary girders satisfy the minimum requirements as indicted in Table 13. Fig. 25 show the natural mode I of the main and auxiliary box girders.

Table 13. The results of the natural frequencies computations for the main and auxiliary box girders.

\begin{tabular}{ccc}
\hline \multirow{2}{*}{ Natural mode } & \multicolumn{2}{c}{ Natural frequency $(\mathrm{Hz})$} \\
\cline { 2 - 3 } & Main girder & Auxiliary girder \\
\hline I & 14.9001 & 11.0365 \\
II & 15.2601 & 13.5584 \\
III & 16.1740 & 16.5402 \\
IV & 21.7111 & 18.2878 \\
V & 23.1754 & 30.5637 \\
\hline
\end{tabular}

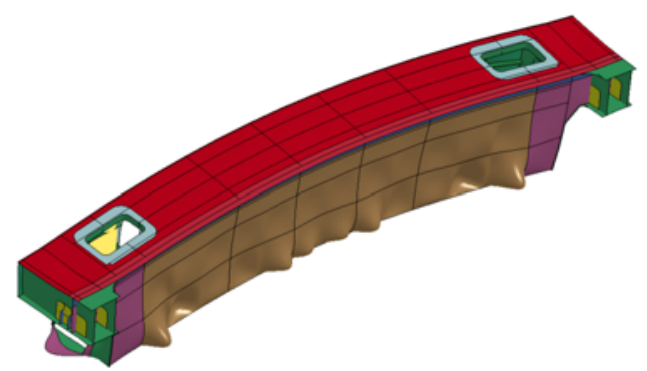

(a) Main girder (amplified by 35)

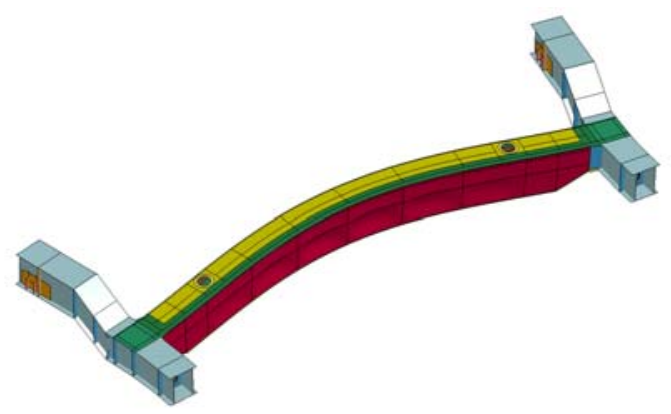

(b) Auxiliary girder (amplified by 2)

Fig. 25. The natural mode I of the main and auxiliary box girders.

\subsection{Recommended Practices}

The ULS based safety factor of the reference box girder crane structures using SM490 which were originally designed using the AWSDM was found in the present 
study. Also, the safety factor $\alpha$ in Equation (4) for the new designs of the main and auxiliary box girder crane structures using HSB500 are given by $\alpha=3.41$ and $\alpha=$ 4.09, respectively, where $\gamma_{c}=1.0$ was taken in Equation (3).

As per the requirement of the manufacturer, the safety margins of the main and auxiliary box girder structures have been kept at the similar level to the original design. However, it is considered that the structural weight of the new design can be further reduced, considering that the safety margin is quite large. In the industry practice, the structural safety factor is often taken as $\alpha=1.15$ for stiffened panels and girders [50].

\section{Concluding Remarks}

The objective of the present study has been to redesign an existing box girder crane structures using the limit state approach with the focus on the ultimate limit states and the serviceability limit states. The original structures were made of SM490 steel and designed using the allowable working stress based method. The manufacturer of the crane wanted to make the structures using HSB500 steel and to redesign them applying an advanced design technology.

For this purpose, the ultimate strength behaviour and the safety factor of the original structures was identified by the nonlinear finite element method. By keeping the safety factor of the crane structures at the same (or similar) level as the original design, new structural designs using HSB500 steel were developed by minimizing the structural weight.

It is found that the reduction of the structural weight in the new design of the main box girder crane structures is 5.60 tonf or $10.2 \%$ of the original structures, where the safety factor based on the ultimate strength is 3.41 , while the safety factor of the original design is 3.38 . Similarly, the reduction of the structural weight in the new design of the auxiliary box girder crane structures 1.56 tonf or $10.8 \%$ of the original structures, where the safety factor based on the ultimate strength is 4.09 , while the safety factor of the original design is 3.97 . 
Based on the studies, it is concluded that the ultimate limit state design method is much better than the allowable working stress design method in terms of designing more economical, yet safe structures. This benefit is obviously due to the fact the former method is unable to determine a realistic factor of the structural safety which is determined as a ratio of the ultimate strength or maximum load-carrying capacity to the design loads, although it remains unknown in the latter method.

It is hoped and believed that the insights and practices developed in the present study will be useful for the optimum design of box girder crane structures using the limit state approach. While the present study presents the design results associated with the ultimate limit states and the serviceability limit states, those for the fatigue limit states will be presented in a separate paper.

\section{Acknowledgements}

This study was undertaken in the International Centre for Advanced Safety Studies of the Korea Ship and Offshore Research Institute at Pusan National University, South Korea which has been a Lloyd's Register Foundation Research Centre of Excellence since 2008.

\section{References}

[1] B. Johansson, M. Velijkovic, Steel plated structures, Progress in Structural Engineering and Materials, 3 (1) (2001), pp. 13-27.

[2] J.K. Paik, Ultimate limit state analysis and design of plated structures, Second edition, Chichester, UK (2018).

[3] J.K. Paik, A.K. Thayamballi, Some recent developments on ultimate limit state design technology for ships and offshore structures, Ships and Offshore Structures, 1 (2) (2006), pp. 99-116.

[4] J.K. Paik, Ultimate limit state performance of oil tanker structures designed by IACS common structural rules, Thin-Walled Structures, 45 (12) (2007), pp. 1022-1034. 
[5] I. Lotsberg, Recent advances on fatigue limit state design for FPSOs, Ships and Offshore Structures, 2 (1) (2007), pp. 49-68.

[6] J. Czujko, J.K. Paik, A new method for accidental limit states design of thin-walled structures subjected to hydrocarbon explosion loads, Ships and Offshore Structures, 10 (5) (2015), pp. 460-469.

[7] X. Zhang, J.K. Paik, N. Jones, A new method for assessing the shakedown limit state associated with the breakage of a ship's hull girder, Ships and Offshore Structures, 11 (1) (2015), pp. 92-104.

[8] K. Riska, R. Brides, Limit state design and methodologies in ice class rules for ships and standards for Arctic offshore structures, Marine Structures, In Press, DOI: 10.1016/j.marstuc.2017.09.005

[9] I. Iskhakov, Y. Ribakov, A new concept for design of fibered high strength reinforced concrete elements using ultimate limit state method, Material and Design, 51 (2013), pp. 612-619.

[10] R. Vaz Rodrigues, A new technique for ultimate limit state design of arbitrary shape RC sections under biaxial bending, Engineering Structures, 104 (2015), pp. 1-17.

[11] M. Cacho-Perez, Design and analysis of an industrial steel building. Limit states, stability check, Engineering Structures, 153 (15) (2017), pp. 342-353.

[12] D. Leshchinsky, B. Leshchinsky, O, Leshchinsky, Limit state design framework for geosynthetic-reinforced soil structures, Geotextiles and Geomembranes, 45 (6) (2017), pp. 642-652

[13] A.K. Bhowmick, G.Y. Grondin, Limit state design of steel columns reinforced with welded steel plates, Engineering Structures, 114 (2016), pp. 48-60.

[14] J.K. Paik, J.K. Seo, Nonlinear finite element method models for ultimate strength analysis of steel stiffened-plate structures under combined biaxial compression and lateral pressure actions-Part I: Plate elements, Thin-Walled Structures., 47 (8-9) (2009), pp. 1008-1017. 
[15] J.K. Paik, J.K. Seo, Nonlinear finite element method models for ultimate strength analysis of steel stiffened-plate structures under combined biaxial compression and lateral pressure actions-Part II: Stiffened panels, Thin-Walled Structures., 47 (8-9) (2009), pp. 998-1007.

[16] S. Zhang, I. Khan, Buckling and ultimate capability of plates and stiffened panels in axial compression, Marine Structures, 22 (4) (2009), pp. 791-808.

[17] G. Wang, H. Sun, H. Peng, R. Uemori, Buckling and ultimate strength of plates with openings, Ships and Offshore Structures, 4 (1) (2009), pp. 43-53.

[18] U.N. Kim, I.H. Choe, J.K. Paik, Buckling and ultimate strength of perforated plate panels subject to axial compression: experimental and numerical investigations with design formulations, Ships and Offshore Structures, 4 (4) (2009), pp. 337-361.

[19] N. Yang, P.K. Das, X. Yao, Ultimate strength and reliability assessment of laminated composite plates under axial compression, Ships and Offshore Structures, 6 (1-2) (2011), pp. 105-113.

[20] I. Khan, S. Zhang, Effects of welding-induced residual stress on ultimate strength of plates and stiffened panels, Ships and Offshore Structures, 6 (4) (2011), pp. 297-309.

[21] P.A. Frieze, M. Abbatista, M. Vallascas, J.K. Paik, A benchmark study of ISO-18072-2 on the stiffened panel ultimate strength. In: Proceedings of the 30th International Conference on Ocean, Offshore and Arctic Engineering (OMAE2011), Rotterdam, Netherlands (2011), 19-24 June.

[22] O.F. Hughes, J.K. Paik, Ship structural analysis and design, The Society of Naval Architects and Marine Engineers, Alexandria, VA, USA (2013).

[23] S.R. Cho, H.S. Kim, H.M. Doh, Y.K. Chon, Ultimate strength formulation for stiffened plates subjected to combined axial compression, transverse compression, shear force and lateral pressure loadings, Ships and Offshore Structures, 8 (6) (2013), pp. 628-637. 
[24] S. Zhang, A review and study on ultimate strength of steel plates and stiffened panels in axial compression, Ships and Offshore Structures, 11 (1) (2016), pp. 81-91.

[25] A. Rahbar-Ranji, A. Zarookian, Ultimate strength of stiffened plates with a transverse crack under uniaxial compression, Ships and Offshore Structures, 10 (4) (2015), pp. 416-425.

[26] Y. Garbatov, M. Tekgoz, C. Guedes Soares, Experimental and numerical strength assessment of stiffened plates subjected to severe non-uniform corrosion degradation and compressive load, Ships and Offshore Structures, 12 (4) (2017), pp. 461-473.

[27] M. Mahendran, N.W. Murray, Ultimate load behaviour of box-columns under combined loading of axial compression and torsion, Thin-Walled Structures, 9 (1-4) (1990), pp. 91-120.

[28] M. Królak, A. Młotkowski, Experimental analysis of post-bucking and collapse behaviour of thin-walled box-section beam, Thin-Walled Structures, 26 (4) (1996), pp. 287-314.

[29] N. Shanmugam, V. Lian, V. Thevendran, Finite element modeling of plate girders with web opennings, Thin-Walled Structures, 40 (2002), pp. 443-464

[30] M. Kotełko, Load-capacity estimation and collapse analysis of thin-walled beams and columns-resent advances, Thin-Walled Structures, 42 (2004), pp. 153-175.

[31] J.M. Gordo, C. Guedes Soares, Experimental evaluation of the behaviour of a mild steel box girder under bending moment, Ships and Offshore Structures, 3 (4) (2008), pp. 347-358.

[32] G. Shi, D. Wang, Residual ultimate strength of open box girders with cracked damage, Ocean Engineering, 43 (2012), pp. 90-101.

[33] S. Saad-Eldeen, Y. Garbatov, C. Guedes Soares, Analysis of plate deflections during ultimate strength experiments of corroded box girders, Thin-Walled Structures, 54 (2012), pp. 164-176. 
[34] C. Graciano, A. Ayestarán, 6. Steel plate girder webs under combined patch loading, bending and shear, Journal of Constructional Steel Research, 80 (2013), pp. 202-212.

[35] R. Chacón, M. Serrat, E. Real, The influence of structural imperfections on the resistance of plate girders to patch loading, Thin-Walled Structures, 53 (2012), pp. 15-25.

[36] S. Saad-Eldeen, Y. Garbatov, C. Guedes Soares, Experimental assessment of corroded steel box-girders subjected to uniform bending, Ships and Offshore Structures, 8 (6) (2013), pp. 653-662.

[37] S. Saad-Eldeen, Y. Garbatov, C. Guedes Soares, Ultimate strength assessment of corroded box girders, Ocean Engineering, 58 (15) (2013), pp. $35-47$.

[38] S. Benson, A. AbuBakar, R.S. Dow, A comparison of computational methods to predict the progressive collapse behaviour of a damaged box girder, Engineering Structures, 48 (2013), pp. 266-280.

[39] S. Saad-Eldeen, Y. Garbatov, C. Guedes Soares, Effect of corrosion severity on the ultimate strength of a steel box girder, Engineering Structures, 49 (2013), pp. 560-571.

[40] J.M. Gordo, C. Guedes Soares, Experimental analysis of the effect of frame spacing variation on the ultimate bending moment of box girders, Marine Structures, 37 (2014), pp. 111-134.

[41] S. Saad-Eldeen, Y. Garbatov, C. Guedes Soares, Strength assessment of a severely corroded box girder subjected to bending moment, Journal of Constructional Steel Research, 92 (2014), pp. 90-102.

[42] O. Mijušković, B. Ćorić, B. Šćepanović, L. Žugić, Analytical model for buckling analysis of the plates under patch and concentrated loads, Thin-Walled Structures, 101 (2016), pp. 26-42. 
[43] J.M. Underwood, A.J. Sobey, J.I.R. Blake, R.A. Shenoi, Compartment level progressive collapse strength as a method for analysing damaged steel box girders, Thin-Walled Structures, 106 (2016), pp. 346-357.

[44] M. Kotełko, P. Lis, M. Macdonald, Load capacity probabilistic sensitivity analysis of thin-walled beams, Thin-Walled Structures, 115 (2017), pp. $142-153$.

[45] J.K. Paik, A.K. Thayamballi, Ship-shaped offshore installations: design, building, and operation, Cambridge University Press, Cambridge, UK (2007).

[46] ISO 22986, Cranes - stiffness - bridge and gantry cranes, International Organization for Standardization, Geneva (2007).

[47] ANSYS, User's manual (version 18.1), ANSYS Inc., Canonsburg, USA (2017).

[48] AIST, Specification for electric overhead traveling cranes for steel mill service, AIST Technical Report No.6, Association for Iron \& Steel Technology, Warrendale, PA, USA (2005).

[49] EN 1990, Eurocode 0: Basis of structural design, European Committee for Standardization, Brussels, Belgium (2002).

[50] EN 1993, Eurocode 3: Design of steel structures, European Committee for Standardization, Brussels, Belgium (2005). 